\title{
Analysis and Categorization of Several Dendrobium Species Based on Morphological Traits
}

\author{
Nhu-Hoa Nguyen ${ }^{1^{*}}$, Tuan-Loc Le ${ }^{2}$, Huyen-Trang Vu ${ }^{2}$, Kım-Dınh $\operatorname{Tran}^{3}$, \\ Hop $\operatorname{Tran}^{4}$, Hoa-Xo Duong ${ }^{5}$ and Hoang-Dung $\operatorname{Tran}^{2^{*}}$ \\ ${ }^{1}$ Faculty of Biology, Ho Chi Minh City University of Education, 280 An Duong Vuong Street, Ward 4, \\ District 5, Ho Chi Minh 72711, Vietnam. \\ ${ }^{2}$ Faculty of Biotechnology, Nguyen Tat Thanh University, 298A-300A Nguyen Tat Thanh Street, \\ Ward 13, District 4, Ho Chi Minh 72820, Vietnam. \\ ${ }^{3}$ Vietnam Academy of Agricultural Sciences, 121 Nguyen Binh Khiem Street, Ward Da Kao, \\ District 1, Ho Chi Minh 71000, Vietnam. \\ ${ }^{4}$ University of Science, Viet Nam National University, Ho Chi Minh City, 227 Nguyen Van Cu Street, \\ Ward 4, District 5, Ho Chi Minh 72711, Vietnam. \\ ${ }^{5}$ Biotechnology Center of Ho Chi Minh City, 2374 Highway 1, Quarter 2, Ward Trung My Tay, \\ District 12, Ho Chi Minh 71507, Vietnam.
}

\section{Authors' contributions}

This work was carried out in collaboration among all authors. Authors NHN, HTV and HDT designed the study, performed the statistical analysis, wrote the protocol and wrote the first draft of the manuscript. Authors KDT, HT and HXD managed the analyses of the study. Author TLL managed the literature searches. All authors read and approved the final manuscript.

Article Information

DOI: 10.9734/ARRB/2020/v35i330205

Editor(s):

(1) Dr. Bechan Sharma, University of Allahabad, India.

Reviewers:

(1) L. C. De, National Research Centre for Orchids, India. (2) Gonzalo E. Aranda Abreu, Universidad Veracruzana, Mexico. Complete Peer review History: http://www.sdiarticle4.com/review-history/56811

Original Research Article

Received 02 March 2020

Accepted 07 May 2020

Published 19 May 2020

\section{ABSTRACT}

Dendrobium Sw. is the a highly diversified Orchidaceae genus with at least 100 identified species in Vietnam. Classification and description of this genus in Vietnam suffered from a number of setbacks such as lack of synchronization and photographic illustrations, which rendered identification and researches of Dendrobium samples a daunting task. Therefore, this study constructed the database of morphological descriptions along with sample images of forty 
Dendrobium samples in Vietnam. Based on this database, species in the Dendrobium genus were analyzed and categorized to create a clear-illustrated information resource which is easy to use by non-specialized users.

Keywords: Orchid; Dendrobium; morphological traits.

\section{INTRODUCTION}

Dendrobium Sw. is the second most diversified genus among Orchidaceae family - based on both species number and morphology - with over 1600 species [1,2], and this number is increasing due to appearances of new natural and artificial hybrids. The monocotyledonal genus is mostly ephiphytic although lithophytic and terrestrial life forms are observed [3]. It is distributed in many tropical and subtropical regions, amongst which Southeast Asia has hundreds of species and Vietnam has over 100 species distributed widely in the country $[3,4]$. Dendrobium is well known for both its ornamental and medicinal values $[5,6,7,8]$, hence of its species are endangered due to over-collection; moreover habitat loss and fragmentation also contribute to the extinction threats, therefore solid information on taxonomy, phylogeny and breeding, therefore, is essential $[9,10,11]$. However, the genus is also notorious for its difficulty in classification and differentiation based on morphologydue to the huge morphological diversity and vegetative similarity between the species $[8,9,11,12]$.

Various efforts have been done to categorize this orchid genus. According to Tran (1998), there are 100 Dendrobium species in Vietnam classified into 14 sections based on complicated morphological criteria of shoots (pseudobulbs), leaves and flowers [13]. Pham (2003) divided this genus into 13 sections [14]. Duong (1992) arranged Vietnamese Dendrobium into a 15section system [15]. The members of those sections in different systems have also considerable differences. Those classification database provided descriptions in text along with illustration figures which were mostly in drawing forms; the problem is excaberated even more considering the high vegetative similarity and overlapping morphological variation within the species $[11,16]$. Therefore identification of and researches on Dendrobium as well as other orchid species via these database channels are probably difficult for non-professional users such as collectors, hobbyists, novice researchers, and students.

This study, serving education goals, aimed to construct a database of Vietnamese Dendrobium morphological traits. From then analysis and evaluation of genetic relationship based on such features were performed to provide an intuitive, clear and familiar illustration for students. Our results can be served as references for farmers, hobbyists, or novices who just began researches on Dendrobium.

\section{MATERIALS AND METHODS}

\subsection{Materials}

Forty Dendrobium samples were collected from orchid collections of Biotechnology Center of Ho Chi Minh City. Only individuals which were healthy and included full set of shoots, leaves and flowers were chosen.

\subsection{Methods}

Horizontal anatomy analysis: Completebloomed flower was used for gently separating each petal off the flower axis. The petals and receptacles were arranged symmetrically across a plane for taking photographs. Horizontal anatomy characteristics were recorded [17].

Vertical anatomy analysis: Complete-bloomed flower was cut into two equal, laterally symmetric parts. Then the left half part was taken photographs. Vertical anatomy characteristics were recorded [17].

Morphological character description: Roots, stems, leaves and flowers traits were described, respectively, using our own sample features and reference information from characteristics used in distinctness, uniformity and stability (DUS) [18] [19] testing criteria for Cymbidium and Phalaenopsis.

Construction of taxonomic tree: Data of 40 samples was put into Excel program and encoded in binary form in which " 1 " meant data available and " 0 " meant no data available. The data was analyzed by NTSYSpc 2.1 software using UPGMA method, resulted in correlating genealogy diagram of Dendrobium taxa [20]. 


\section{RESULTS AND DISCUSSION}

\subsection{Preliminary Identification of the Samples}

Scientific names were determined based on orchid monographs and verified by professionals. Forty Dendrobium taxa belongs to 37 wild species and 3 hybrids which were $D$. pulchellum "Gatton sunray", D. anosmum x D. aphyllum and $D$. anosmum $x$ D. parishii (Table 1). All of them were then included in orchid collections of Biotechnology Center of Ho Chi Minh City.

Morphological images of 40 Dendrobium samples were recorded in five approaches: whole body, whole inflorescence, whole floret, flower vertical anatomy and flower horizontal anatomy) was recorded. Recorded images were clear, high resolution and edited with dark background to highlight the research objects. Scale bar for a good gauge of the objects real size was also included (Fig. 1).

Whole plant and floral morphological traits were recorded base on examination of distinctness, uniformity and stability (DUS). DUS examination was vital in assessment of novel domestic plant for certification, in plant taxon description and in taxon identification based on distinctive features. As the number of published Dendrobium hybrids is increasing, it is essential to search the DUS criteria in conducting taxon description from morphological traits.

The study recorded 72 morphological features of 40 Dendrobium taxa. The Dendrobium primulinum Linld was recorded to have roots grew under the stem base; multiple pendulous pseudostem with elliptical longitudinal section and circular cross section; ungrooved internodes; slim, linear leaves with acute apex and no undulation, dark green in color, lack of anthocyanin coloration; inflorescences grew in clusters, semi - pendulous pedicels with no anthocyanin; single flowers with horizontally spread petals, none or light floral scent; oblong dorsal sepals slightly bent along the vertical back.

Similar to previous works $[13,14,15]$ all studied samples shared the same morphological traits of Dendrobium genus such as strong roots grew from stem or psedobulb base, multiple stems, nodal pseudobulbs, leaves had smooth surface, no petiole, arranged in two rows concentrated at stem apex, inflorescences grew from leaf axils, had various colors and similar structure with three sepals ( 1 dorsal sepals and 2 lateral sepals with similar sizes and shapes) and three petals (2 upper petals similar to sepals and one labellum with diversified shape). The labellum attracted insects and served as mount for pollinators. The stamen column located at the center with honey inside. Although sharing similar floral structure, each taxa had its own flowers with distinctive shapes and colors which can be used as main morphological criteria for identification and differentiation between taxa. Other morphological traits such as stem and leaf shapes could be employed for distinguishment of species.

Dendrobium taxa usually had 38 chromosomes $(2 n=38)$ [21]. Some taxa had 40 chromosomes and rare exceptions may had 76 or 114 chromosomes. Taxa had the same chromosomal numbers could have very different chromosomal sizes. This might be one of the reasons for the high morphological diversity in Dendrobium.

Taxonomic results (Fig. 2) showed that two taxa $D$. amabile and $D$. palpebrae in section Callista were separated into Group I due to similar leaf and flower shapes. However they were completely secluded from other Dendrobium taxa. The remaining three Callista members $(D$. sulcatum, $D$. densiflorum and $D$. chrysotoxum) shared high morphological similarities therefore were grouped into a distinctive branch of Group IIA; among them $D$. sulcatum and $D$. chrysotoxum shared more similarities than $D$. sulcatum.

Group II was divided into 2 small groups of IIA and IIB. Group IIA had 17 members with only one had pendulous stems; meanwhile 10 of 21 group IIB members had pendulous stem (samples no. 7, 8, 9, 10, 11, 12, 15, 16, 28, 39). D. anosmum $(7,8,9,10)$, D. aphyllum $(11,12)$ and $D$. parishii (28) were highly similar in morphology and had close evolutionary relationships. The hybrid of $D$. anosmum $\times D$. aphyllum was also included in this group. However the hybrid of $D$. anosmum x D. parishii, on the contrary, belonged to a different group along with $D$. hercoglossum, $D$. heterocarpum and $D$. venustum. The two taxa $D$. primulinum and $D$. crepidatum were separted into another monophyletic branch of Group IIB due to high morphological similarities. 
Table 1. Dendrobium taxa in this study

\begin{tabular}{ll}
\hline No. & Scientific name \\
\hline 1 & Dendrobium amabile (Lour.) O' Brien \\
2 & Dendrobium sulcatum Lindl. \\
3 & Dendrobium densiflorum Lindl. \\
4 & Dendrobium chrysotoxum Lindl. \\
5 & Dendrobium palpebrae Lindl. \\
6 & Dendrobium signatum Rchb.f. \\
7 & Dendrobium superbum Lindl. \\
8 & Dendrobium anosmum Lindl. \\
9 & Dendrobium ano4smum Lindl. \\
10 & Dendrobium anosmum Lindl. \\
11 & Dendrobium aphyllum (Roxb.) C.E.C.Fisch. \\
12 & Dendrobium aphyllum (Roxb.) C.E.C.Fisch. \\
13 & Dendrobium pulchellum Roxb. ex Lindl. \\
14 & Dendrobium pulchellum "Gatton sunray “ \\
15 & Dendrobium primulinum Lindl. \\
16 & Dendrobium crepidatum Lindl. \& Paxton \\
17 & Dendrobium capillipes Rchb.f. \\
18 & Dendrobium chryseum Rolfe \\
19 & Dendrobium secundum (BI.) Lindl. ex Wall. \\
20 & Dendrobium devonianum Paxton \\
21 & Dendrobium aduncum Lindl. \\
22 & Dendrobium hercoglossum Rchb. f. \\
23 & Dendrobium crystallinum Rchb. f. \\
24 & Dendrobium intricatum Gagnep. \\
25 & Dendrobium cretaceum Lindl. \\
26 & Dendrobium tortile Lindl. \\
27 & Dendrobium pendulum Roxb. \\
28 & Dendrobium parishii Rchb.f. \\
29 & Dendrobium findlayanum E.C.Parish \& Rchb.f. \\
30 & Dendrobium ellipsophyllum Tang \& F.T Wang \\
31 & Dendrobium draconis Rchb.f. \\
32 & Dendrobium heterocarpum Wall. ex Lindl. \\
33 & Dendrobium suzukii T. Yukawa \\
34 & Dendrobium unicum Seidenf. \\
35 & Dendobium hybrid (D. anosmum x D. parishii) \\
36 & Dendrobium venustum Teijsm. \& Binn. \\
37 & Dendrobium tortile Lindl. \\
38 & Dendrobium hemimelanoglossum Guillaumin \\
39 & Dendobium hybrid (D. anosmum x D. aphyllum) \\
40 & Dendrobium findlayanum E.C.Parish \& Rchb.f. \\
\hline & \\
&
\end{tabular}

\section{Anatomy and morphology description}
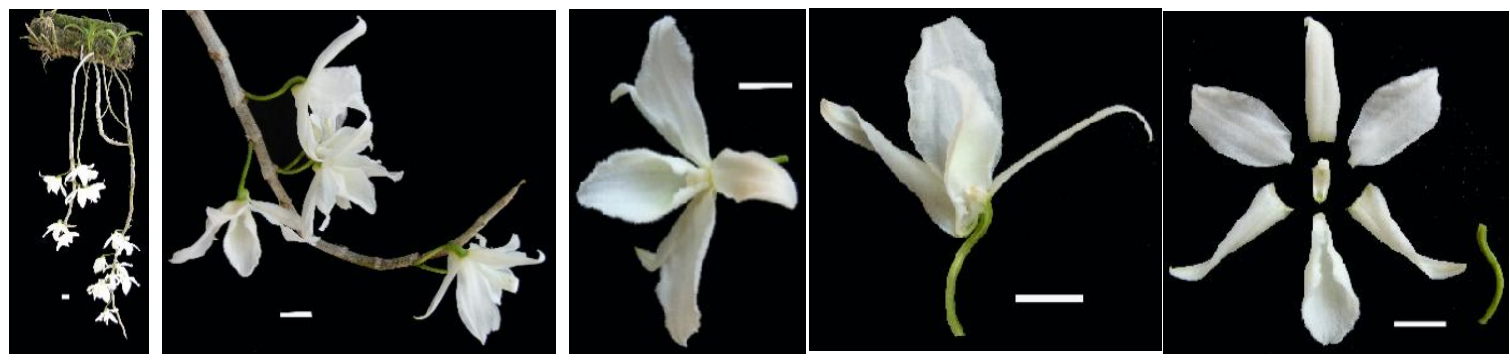

Dendrobium anosmum Lindl. 

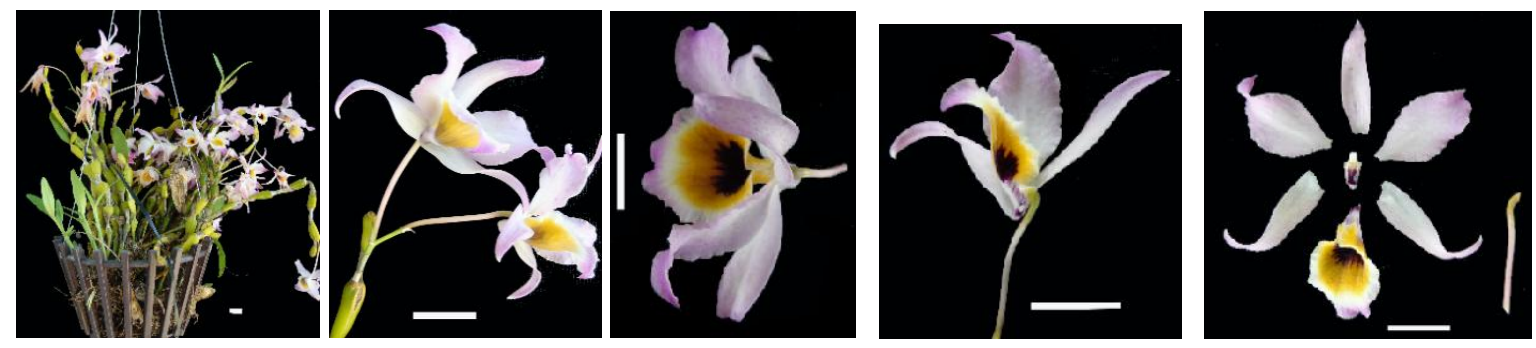

Dendrobiumfindlayanum E.C.Parish \& Rchb.f.

Fig. 1. Anatomy Illustration of $D$. Anosum and $D$. Findlayanum (Scale Bar $=2 \mathrm{~cm}$ )

\section{Construction of taxonomic tree based on morphology}

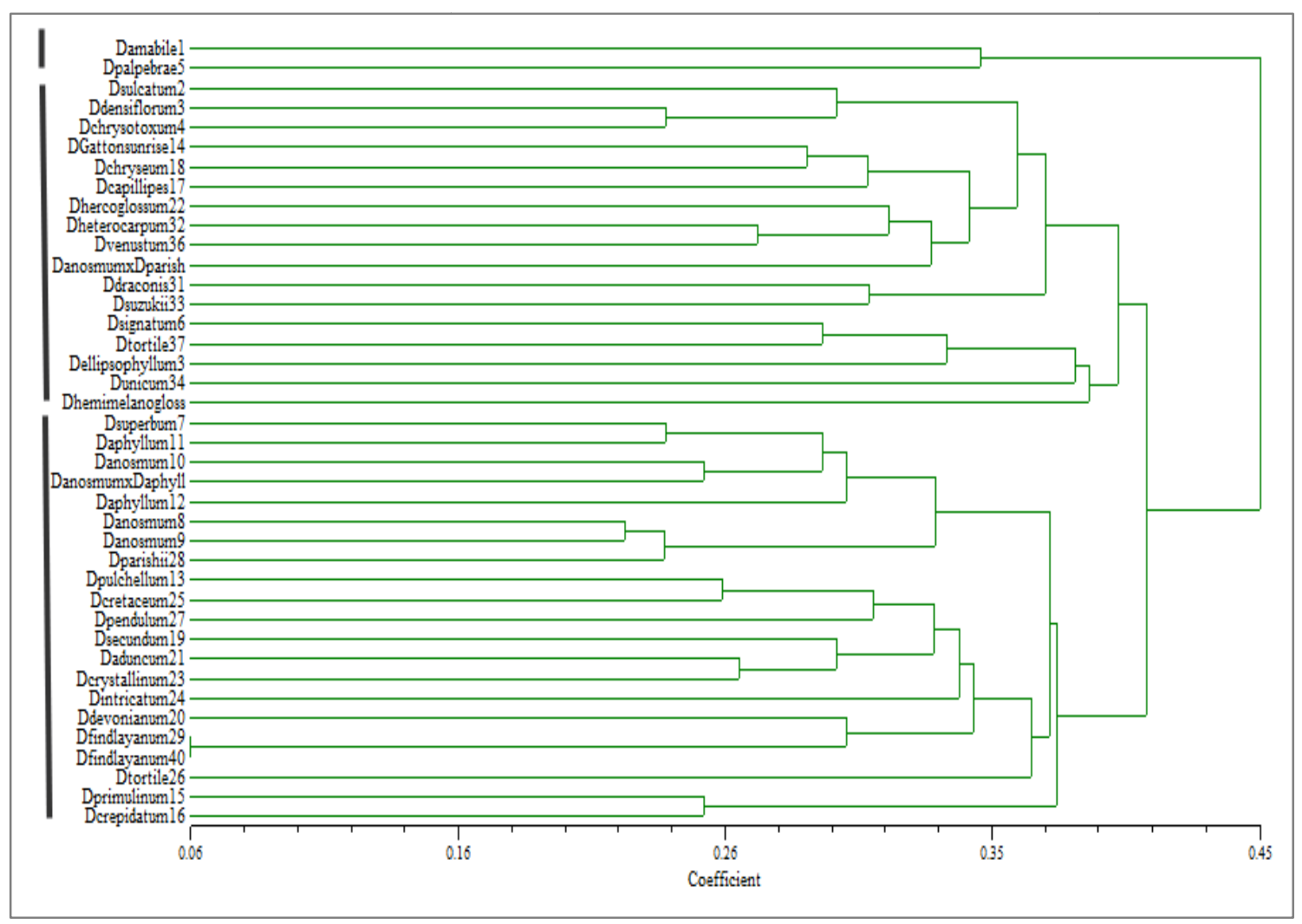

Fig. 2. Taxonomic Tree Constructed Based on Morphological Traits of 40 Studied Dendrobium Samples

Our studied samples belonged to various sections in many classification systems $[13,14,15]$. However based on selected morphological criteria, members of the same section could not be clearly differentiated. Among 21 group IIB taxa, for instance, 16 taxa belonged to Dendrobium section, the $D$. Secundum and $D$. intricatum belonged to Pedilorum and $D$. aduncum belonged to Breviflores section.
Results of this study served as integrated morphological database supplemented for:

1. Worldwide websites which provide information of orchids: scientific names and synonyms, morphological and ecological features... These websites may have none or too few illustrative pictures with no scale ratio and the backgrounds are not in synchronous. 
2. Most orchid websites in Vietnam serve for hobbyists and traders. They provide usable information of orchid name, general descriptions, distribuitions, care guide... and usually have realistic pictures of whole body or inflorescence but often without scale ratio. Vietnam Plant Data Center website provides specific entry for each Dendrobium species but most information is about classification, Vietnamese common name, scientific name, synonyms (if available), a few entries have illustrative pictures (realistitic images of whole body or inflorescence with no scale ratio). Very few taxa have sufficient descriptions of morphology, distribution... these informations are written in English and illustrative images are sufficient with good quality. Some websites mistakenly considered Dendrobium as species. In general these orchid websites do not have adequate quality and reliability.

3. Orchid monographs and plant taxonomy textbooks are limited in Vietnam. Most of them begin with classification then proceed to morphological description, illustrate with detailed images but lack synchronicity. For examples, some taxa are shown whole body, one flower, floral anatomy pictures and even floral diagram with detailed scale ratio but other taxa are shown whole body illustration with no ratio, low quality images, some works have no illustration at all. The most updated work "The Orchidof Vietnam Illustrated Survey" only provides illustrative pictures for just a few taxa [1].

4. References and guidebooks for orchid cultivation were published in considerable number. Such documents do not provide much information of specific species, and use incorect terms. Many authors even wrongly consider Dendrobium as species or family. Illustrations have good quality but are not scientific, few in number, inconsistent in all the taxa and have no scale ratio. For example the "Orchid cultivation and care" guidebook has horizontal section pictures for 4 orchid genera but has no illustration for Dendrobium taxa [22].

The study results can also be used in teaching of botany-related contents in elementary schools. Dendrobium is an orchid genus with disnticntive ecology and anatomy (especially floral anatomy) and also familiar to human life but rarely touched in educational textbooks. The resulted data can also be used in high school and higher education in lectures of plant taxonomy and morphological anatomy.

\section{CONCLUSION}

This study managed to construct a database of morphological traits, illustrative images and a taxonomical tree for 40 taxon samples of the orchid Dendrobium genus. This database can be used in teaching of botany-related contents in general or orchids and Dendrobium in specific. It can also serve as references for other users such as cultivators and hobbyists.

\section{ACKNOWLEDGEMENT}

We would like to thank Ho Chi Minh City University of Education, Nguyen Tat Thanh University and Biotechnology Center of $\mathrm{Ho}$ Chi Minh City supporting the facilities to do this research.

\section{COMPETING INTERESTS}

Authors have declared that no competing interests exist.

\section{REFERENCES}

1. Darmawati IAP, Rai IN, Dwiyani R, Astarini IA. The diversity of wild Dendrobium (Orchidaceae) in Central Bali, Indonesia Biodiversitas. 2018;19(3):1110-6.

2. De LC, Rao AN, Rajeeva PK, Srivastava M. Morphological characterization in Dendrobium species. J Biosci. 2015;4(1): 1198-1215.

3. Moudi M, Go R, Yong CSY, Saleh MN. A Review on Molecular Systematic of the Genus Dendrobium Sw. Acta Biol Malays. 2013;2(2):71-78.

4. Tran DD, Khuat HT, La TN, Nguyen TTT, Pham BH, Tran HD. Identification of Vietnamese Native Dendrobium Species Based on Ribosomal DNA Internal Transcribed Spacer Sequence. Adv Stud Biol. 2018;10 (1):1-12.

5. $\quad$ Feng $S$, Jiang $Y$, Wang $S$, Jiang $M$, Chen $Z$, Ying $Q$, Wang $H$. Molecular Identification of Dendrobium Species (Orchidaceae) Based on the DNA Barcode ITS2 Region and Its Application for Phylogenetic Study. Int J Mol Sci. 2015; 16(9):21975-88.

6. Niu SC, Huang J, Xu Q, Li PX, Yang HJ, Zhang $Y Q$, Zhang GQ, Chen LJ, Niu YX, 
Luo YB, Liu ZJ. Morphological Type Identification of Self-Incompatibility in Dendrobium and Its Phylogenetic Evolution Pattern. Int J Mol Sci. 2018;19(9):2595.

7. Wanitprapha K, Yokoyama KM, Nakamoto ST, Leonhardt KW, Halloran JM. Dendrobium Fact Sheet 13. Department of Agricultural and Resource Economics College of Tropical Agriculture and Human Resources, University of Hawaii. 1991. Avaliable:https://scholarspace.manoa.haw aii.edu/bitstream/10125/54681/CtahrpsEco nFact13Dendro.pdf

8. Wang Y, Wang Z, Diao J, Sun X, Luo Z, Li G. Discrimination of Different Species of Dendrobium with an Electronic Nose Using Aggregated Conformal Predictor. Sensors (Basel). 2019;19(4):964.

9. Liu H, Fang C, Zhang T, Guo L, Ye Q. Molecular authentication and differentiation of Dendrobium species by rDNA ITS region sequence analysis. AMB Express. 2019;9(1):53.

10. Teixeira da Silva JA, Jin X, Dobránszki J, et al. Advances in Dendrobium molecular research: Applications in genetic variation, identification and breeding. Mol Phylogenet Evol. 2016;95:196-216.

11. Xu S, Li D, Li J, Xiang X, Jin W, Huang W, et al. Evaluation of the DNA barcodes in Dendrobium (Orchidaceae) from mainland Asia. PLoS One. 2015;10(1):e0115168.

12. Takamiya $T$, Wongsawad $P$, Sathapattayanon A, Tajima N, Suzuki S, Kitamura S, et al. Molecular phylogenetics and character evolution of morphologically diverse groups, Dendrobium section Dendrobium and allies. AoB Plants. 2014;6:plu045.
13. Tran H. Việt Nam Orchid. Hanoi: Agriculture publishing house; 1998. (in Vietnamese)

14. Pham HH.Việt Nam Plants III. HCMC: Tre publishing house; 2003. (in Vietnamese)

15. Duong DH.Flora of VietNam (9). Hanoi: Science and technics publishing house; 2007 (in Vietnamese).

16. Averyanov L. The Orchid of Vietnam Illustrated Survey Part 2: Subfamilies Orchidoideae. Turczaninowia. 2010;13(2): 5-98.

17. Tran CK. Practical anatomy and morphology of the plant. Hanoi: Hanoi University and Vocational School Publisher; 1981. (in Vietnamese)

18. De LC, Rao AN, Rajeevan PK, Sood SK, Rawat GS. Guidelines for the Conduct of Test for Distinctiveness, Uniformity and Stability on Dendrobium. Protection of Plant Varieties and Farmers' Rights Authority (PPV \& FRA) Government of India; 2009.

19. UPOV. Revised general introduction to the guidelines for the conduct of tests for distinctness, homogeneity and stability of new varieties of plants. UPOV TG/1/2, 11; 1999.

20. Bui CB, Nguyen TL. Genetic Quantity Curriculum. HCMC Nong Lam University, Viet Nam (in Vietnamese); 2003.

21. Wilfret GJ, Takeshita T, Kamemoto $\mathrm{H}$. Genome and karyotype relationships in Dendrobium (Orchidaceae) III Meiotic behavior. J Amer Soc Hort Sci. 1979;104: 43-6.

22. Tran H. Orchid cultivation and care. Hanoi: Agriculture publishing house; 2015. (in Vietnamese)

\section{APPENDIX}

\section{Guidelines for plant anatomy description}

1. Roots: (1) Grow from the axils; (2) Grow below the stem base; (3) Have root tubers.

2. Stem forms: (1) Single; (2) Multiple - erect; (3) Multiple - pendulus, (4) No stem; (5) Have stem tubers.

3. Shape in longitudinal section of pseudobulb: (1) Oblong, (2) Elliptic, (3) Circular, (4) Ovate.

4. Shape in cross section of pseudobulb: (1) Elliptic, (2) Circular.

5. Leaf shape: (1) Narrow lanceolate, (2) Linear, (3) Oblanceolate, (4) Spatulate.

6. Apex leaf shape: (1) Acute, (2) Obtuse, (3) Emarginate. 
7. Symmetry of apex leaf: (1) Asymmetric, (2) Symmetric.

8. Leaf cross-section: (1) Straight, (2) Concave.

9. Twisting of leaf: (1) absent or very weak, (2) Weak, (3) Medium, (4) Strong, (5) Very strong.

10. Leaf greeness: (1) Light, (2) Medium, (3) Dark.

11. Anthocyanin coloration of leaf sheath: (1) Absent, (2) Present.

12. Type of inflorescence: (1) Solitary; (2) Raceme.

13. Attitude of peduncle: (1) Erect, (2) Semi-erect, (3) Horizontal, (4) Semi-pendulous, (5) Pendulous.

14. Anthocyanin coloration of peduncle: (1) Absent, (2) Present.

15. Floral forms: (1) Simple, (2) Semi-double, (3) Double.

16. General impression of petals and sepals: (1) All incurved, (2) Some incurved, some spreading, (3) All spreading, (4) Some spreading, some reflexed, (5) All reflexed, (6) Some incurved, some reflexed.

17. Dorsal sepal shape: (1) Lanceolate, (2) Linear, (3) Oblong, (4) Elliptic, (5) Obovate.

18. Curvature of dorsal sepal longitudinal axis: (1) Incurved with reflexed apex, (2) Strongly incurved, (3) Slightly incurved, (4) Straight, (5) Slightly reflexed, (6) Strongly reflexed, (7) Reflexed with apex.

19. Shape of dorsal sepal apex: (1) Narrow acute, (2) Acute, (3) Obtuse, (4) Truncate, (5) Emarginate.

20. Recurvature of dorsal sepal margins: (1) Absent or very weak, (2) Weak, (3) Medium, (4) Strong, (5) Very strong.

21. Undulation of dorsal sepal margins: (1) Absent or very weak, (2) Weak, (3) Medium, (4) Strong, (5) Very strong.

22. Lateral sepal shape: (1) Lanceolate, (2) Linear, (3) Oblong, (4) Elliptic, (5) Obovate.

23. Curvature of lateral sepal longitudinal axis: (1) Incurved with reflexed apex, (2) Strongly incurved, (3) Slightly incurved, (4) Straight, (5) Slightly reflexed, (6) Strongly reflexed, (7) Reflexed with incurved apex.

24. Shape of lateral sepal apex: (1) Narrow acute, (2) Acute, (3) Obtuse, (4) Truncate, (5) Emarginate.

25. Recurvature of lateral sepal margins: (1) Absent or very weak, (2) Weak, (3) Medium, (4) Strong, (5) Very strong.

26. Undulation of lateral sepal margins: (1) Absent or very weak, (2) Weak, (3) Medium, (4) Strong, (5) Very strong.

27. Number of sepal colors: (1) one, (2) two, (3) three, (4) more than three.

28. Sepal spots: (1) Absent, (2) Presented.

29. Sepal stripes: (1) Absent, (2) Presented.

30. Petal spots: (1) Absent, (2) Presented.

31. Petal stripes: (1) Absent, (2) Presented. 
32. Petal shape: (1) Rhombic, (2) Linear, (3) Oblong, (4) Elliptic, (5) Obovate, (6) Spatulate.

33. Curvature of petal longitudinal axis: (1) Incurved with reflexed apex, (2) Strongly incurved, (3) Slightly incurved, (4) Straight, (5) Slightly reflexed, (6) Strongly reflexed, (7) Reflexed with incurved apex.

34. Shape of petal apex: (1) Narrow acute, (2) Acute, (3) Obtuse, (4) Truncate, (5) Emarginate.

35. Recurvature of petal margins: (1) Absent or very weak, (2) Weak, (3) Medium, (4) Strong, (5) Very strong.

36. Undulation of petal margins: (1) Absent or very weak, (2) Weak, (3) Medium, (4) Strong, (5) Very strong.

37. Number of petal colors: (1) one, (2) two, (3) three, (4) more than three.

38. Lip shape: (1) Narrowly triangular, (2) Triangular, (3) Trapezium, (4) Circular, (5) Oblate, (6) Spatulate.

39. Curvature of lip longitudinal axis: (1) Incurved with reflexed apex, (2) Strongly incurved, (3) Slightly incurved, (4) Straight, (5) Slightly reflexed, (6) Strongly reflexed, (7) Reflexed with incurved apex.

40. Lobes at petal apex: (1) Not lobed, (2) Lobed.

41. Recurvature of lip margins: (1) Absent or very weak, (2) Weak, (3) Medium, (4) Strong, (5) Very strong.

42. Undulation of lip margins: (1) Absent or very weak, (2) Weak, (3) Medium, (4) Strong, (5) Very strong.

43. Number of lip colors: (1) one, (2) two, (3) three, (4) more than three.

44. Lip spots: (1) Absent, (2) Presented.

45. Lip stripes: (1) Absent, (2) Presented.

46. Leaf upper side color: (1) Green; (2) Grained; (3) Stripped; (4) Waxy

47. Leaf lower surface color: (1) Green; (2) Grained; (3) Stripped; (4) Waxy

48. Dorsal sepal color: (1) White, crystal; (2) Pink, tea; (3) Light green, dark green; (4) Violet; (5) Yellow, orange; (6) Yellowish brown

49. Dorsal sepal features: (1) Red/violet spots; (2) Reddish brown spots; (3) Violet stripes; (4) Reddish brown stripes; (5) Green stripes; (6) None

50. Dorsal sepal smoothness: (1) Wrinkled; (2) Smooth

51. Dorsal sepal hairiness: (1) Hairy; (2) No hair

52. Lateral sepal color: (1) White, crystal; (2) Pink, tea; (3) Light green, dark green; (4) Violet; (5) Yellow, orange; (6) Red, (7) Yellowish brown

53. Lateral sepal features: (1) Red/violet spots; (2) Reddish brown spots; (3) Violet stripes; (4) Reddish brown stripes; (5) Green stripes; (6) None

54. Lateral sepal smoothness: (1) Wrinkled; (2) Smooth

55. Lateral sepal hairiness: (1) Hairy; (2) No hair

56. Petal color: (1) White, crystal; (2) Pink, tea; (3) Light green, dark green; (4) Violet; (5) Yellow, orange; (6) Yellowish brown 
57. Petal features: (1) Red/violet spots; (2) Reddish brown spots; (3) Green spots; (4) Violet stripes; (5) Reddish brown stripes; (6) None
58. Petal smoothness:
(1) Wrinkled;
(2) Smooth

59. Petal hairiness: (1) Hairy; (2) No hair

60. Lip form: (1) Tubular; (2) Columnar; (3) Lamellar.

61. Lip color: (1) White, crystal; (2) Pink, tea; (3) Light green, dark green; (4) Violet; (5) Yellow, orange; (6) Yellowish brown

62. Lip features: (1) Red/violet spots; (2) Reddish brown spots; (3) Turmeric spots; (4) White spots, yellow spots; (5) Violet stripes; (6) None

63. Lip smoothness: (1) Wrinkled; (2) Smooth

64. Lip hairiness: (1) Hairy; (2) No hair

65. Lip margin: (1) Fringed/Hairy; (2) Smooth

66. Inflorescence growth pattern: (1) From terminal buds; (2) From stem base; (3) From axil

67. Fragrantness: (1) Strong and lasting; (2) Light and ephemeral; (3) Weak; (4) None.

68. Fragrant period: (1) Day; (2) Night.

69. Flowering time: (1) Spring; (2) Summer; (3) Autumn; (4) Winter; (5) Perpetual.

70. Phyllotaxis: (1) Spiral; (2) Alternate.

71. Winter foliage: Yes/No.

Sample photographic illustrations
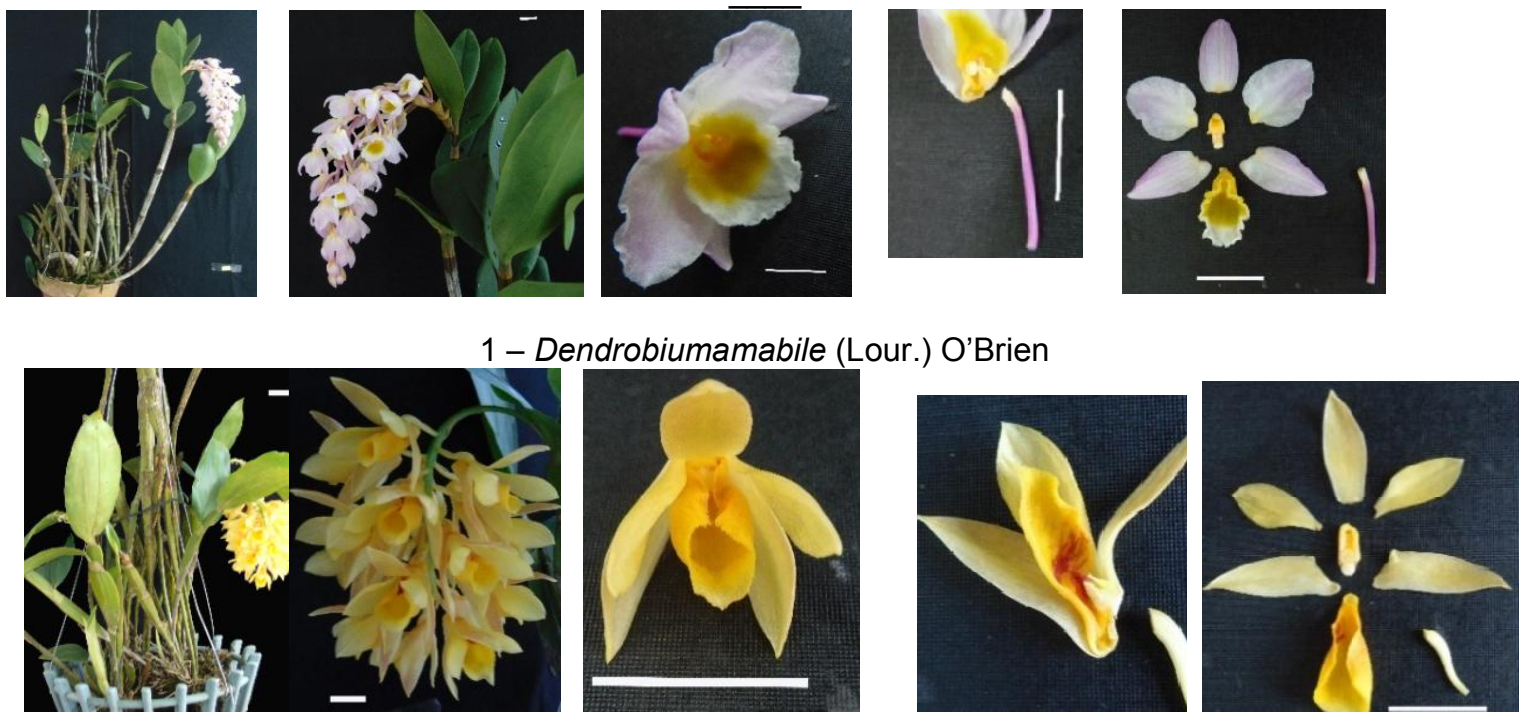

2 - Dendrobium sulcatum Lindl. 

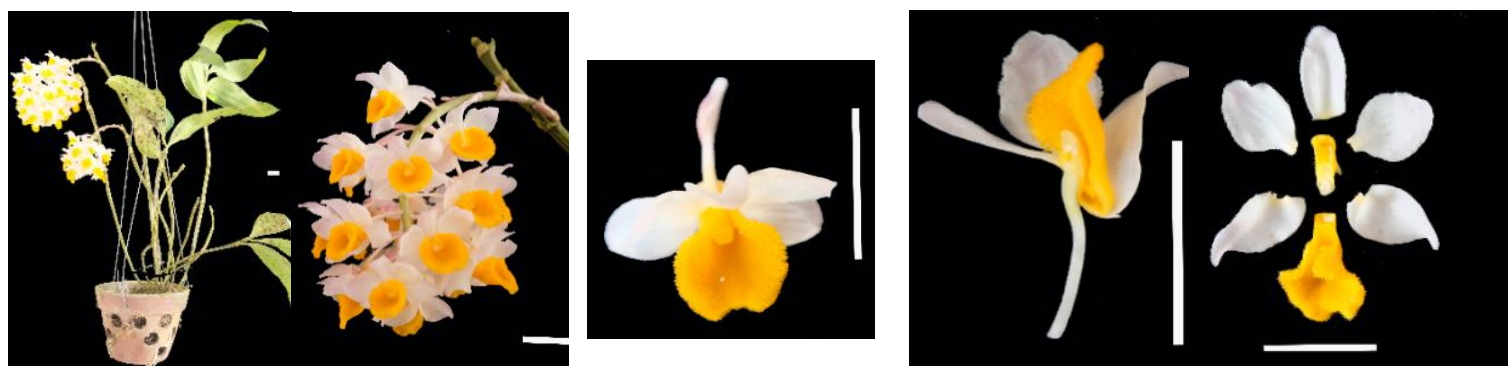

3 - Dendrobium densiflorum Lindl.
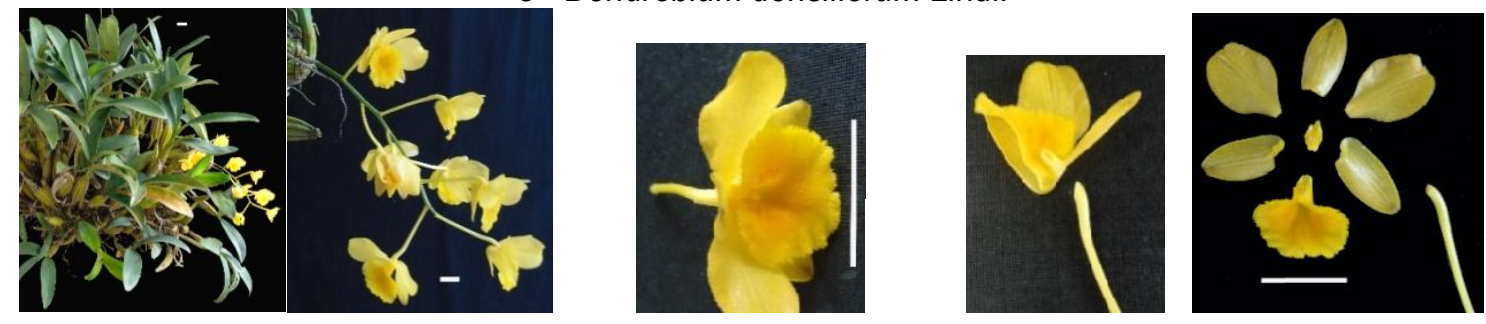

4 - Dendrobium chrysotoxum Lindl
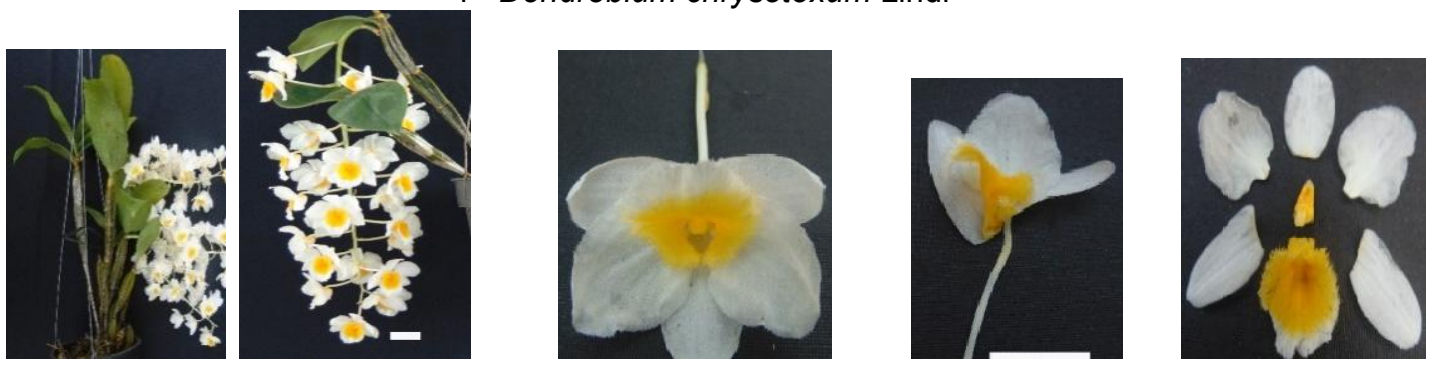

5 - Dendrobium palpebrae Lindl.
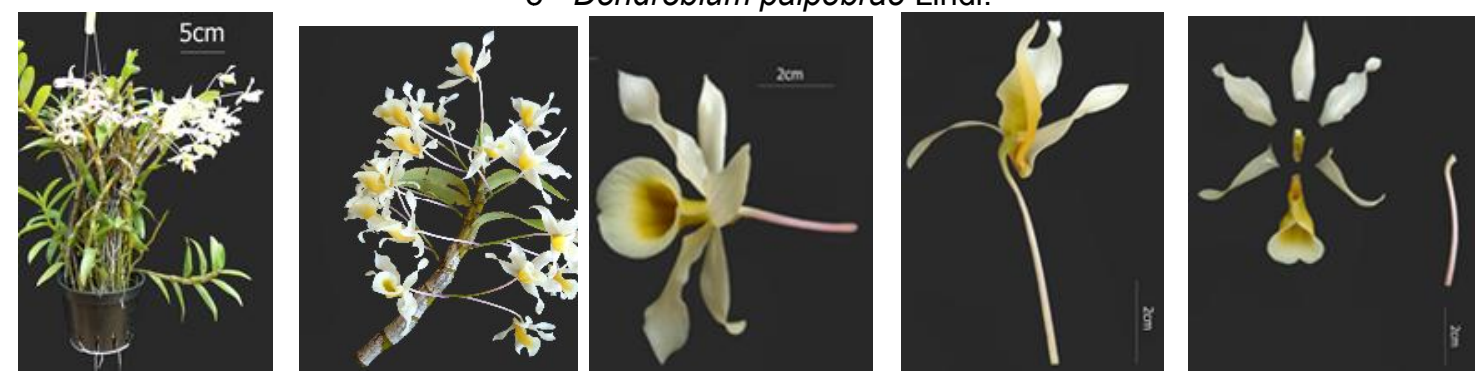

6 - Dendrobium signatum Rchb.f.
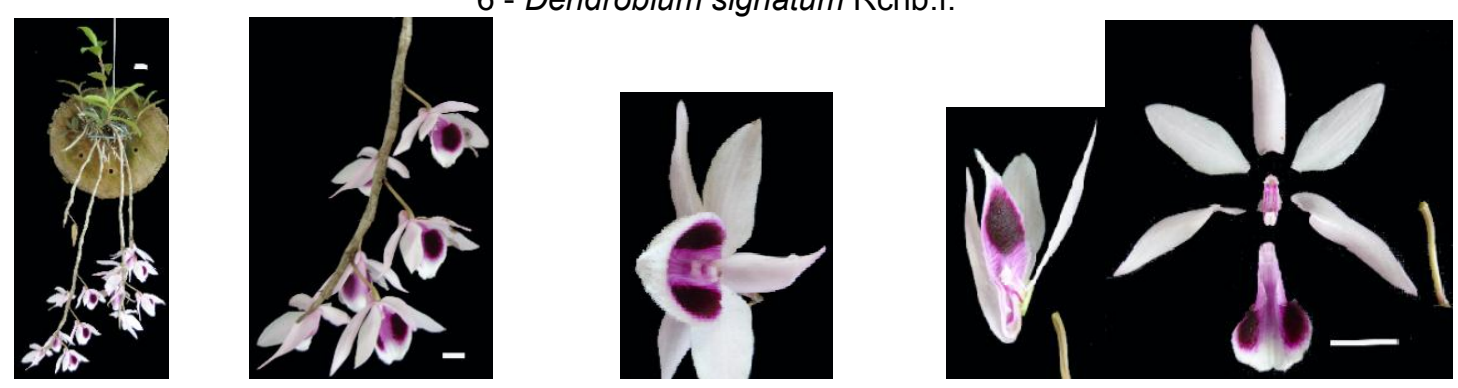

7 - Dendrobium superbum 

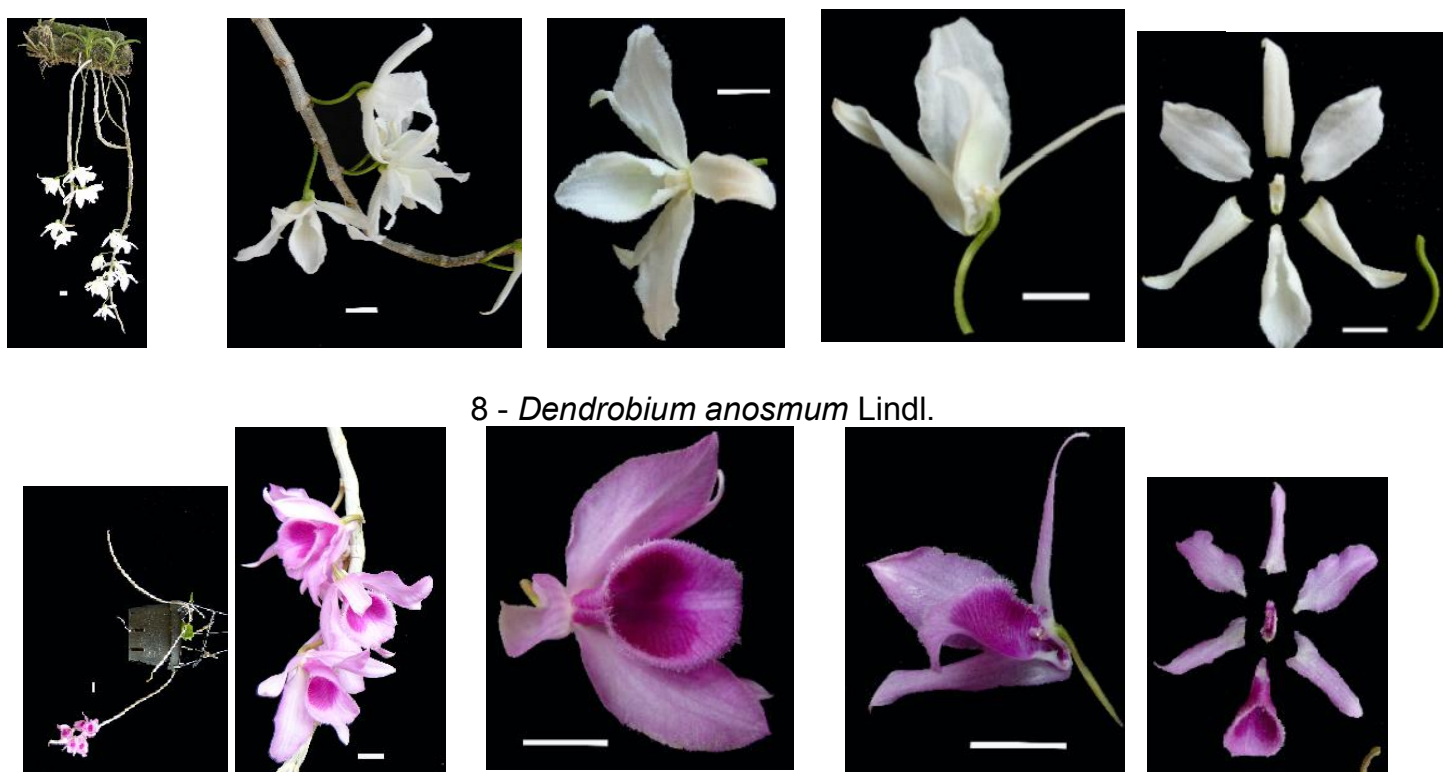

8 - Dendrobium anosmum Lindl.
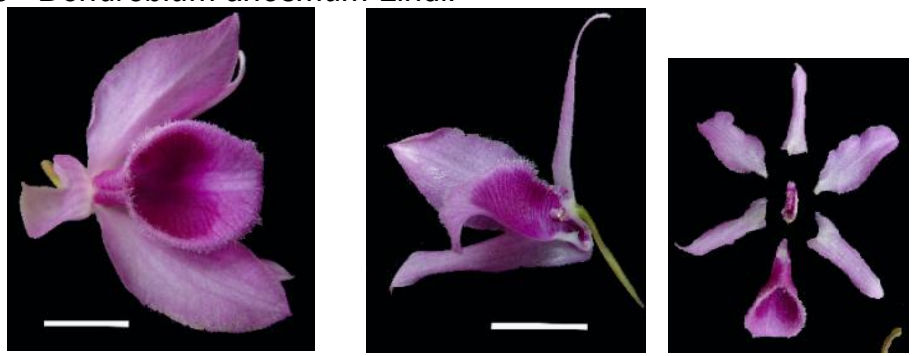

\section{9 - Dendrobium anosmum}
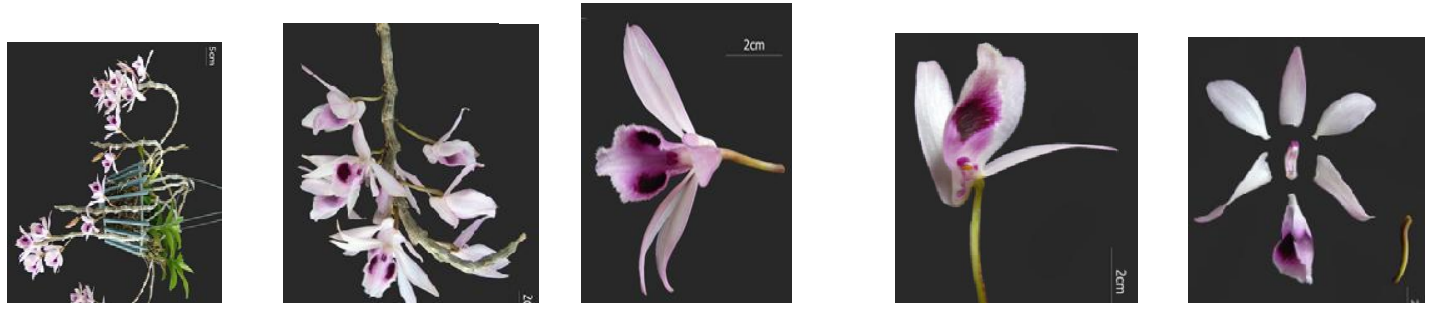

10 - Dendrobium anosmum var alba
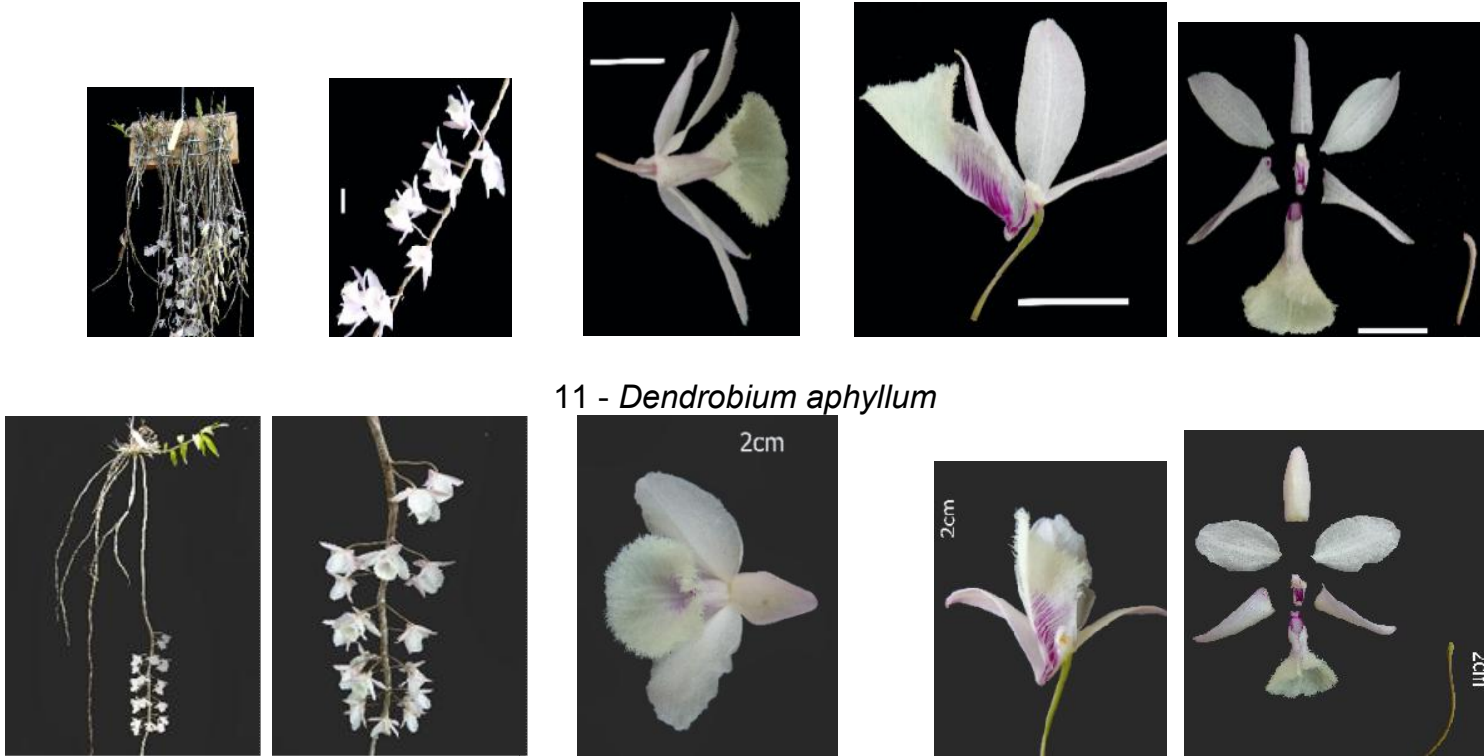

11 - Dendrobium aphyllum
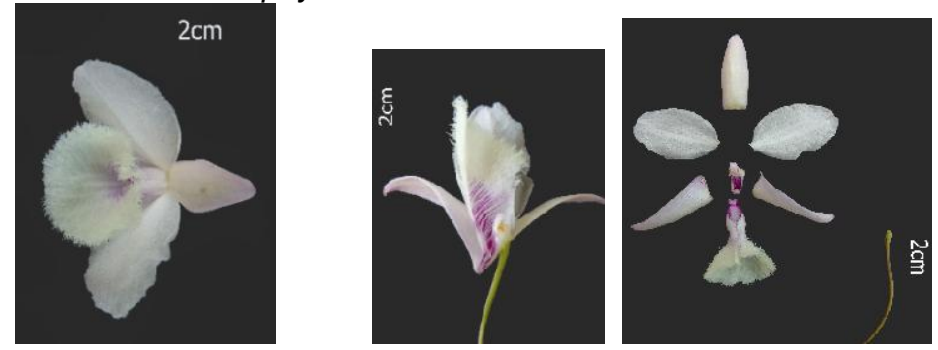

12 - Dendrobium aphyllum (Roxb.) C.E.C.Fisch. 

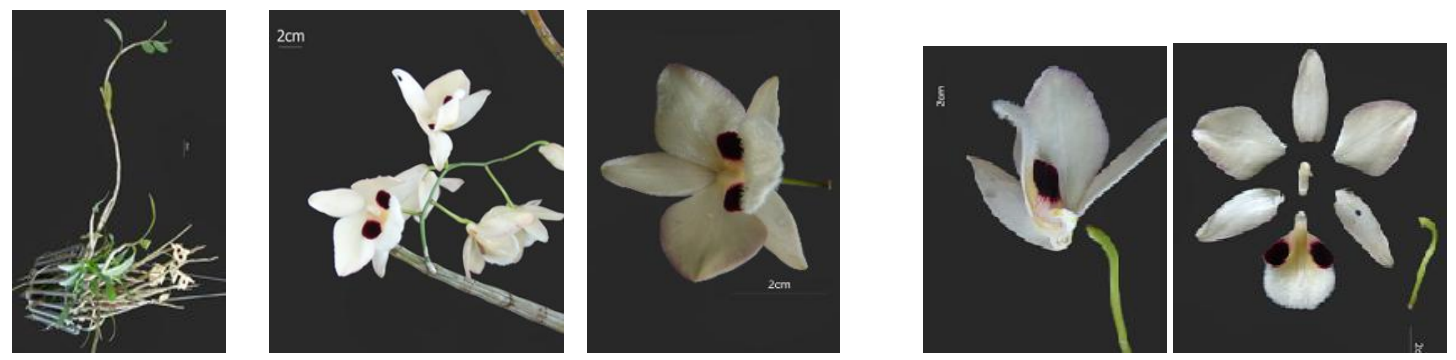

13 - Dendrobium pulchellum Roxb. ex Lindl.
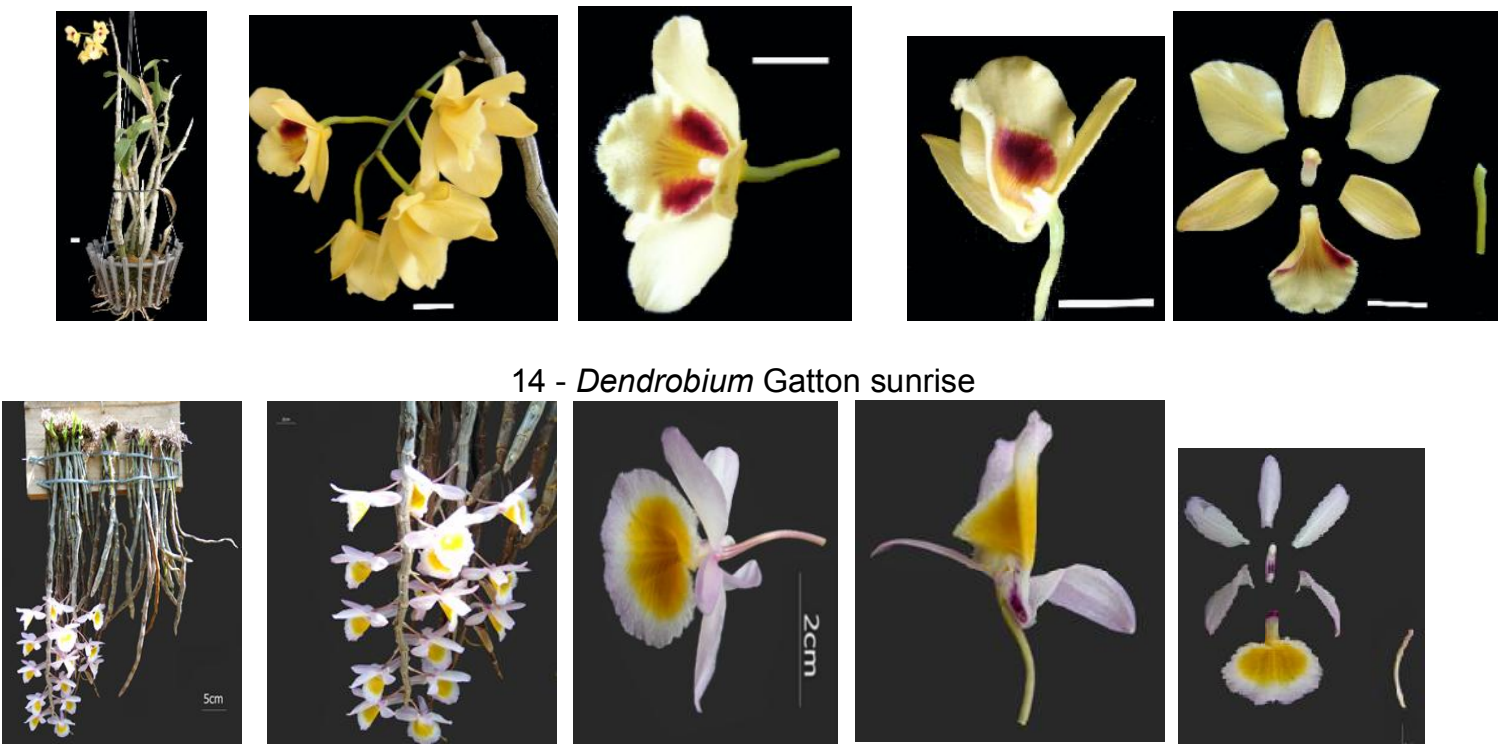

15 - Dendrobium primulinum Lindl..
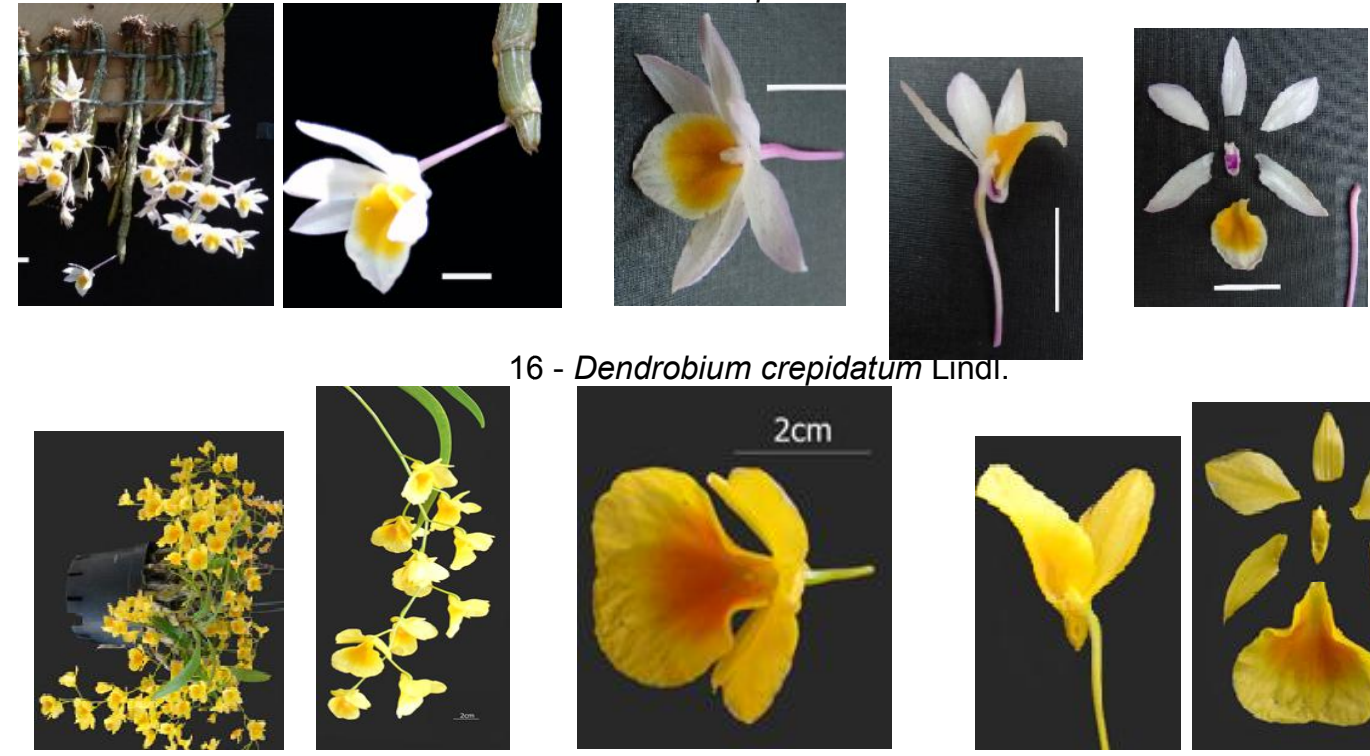

16 - Dendrobium crepidatum LInal.
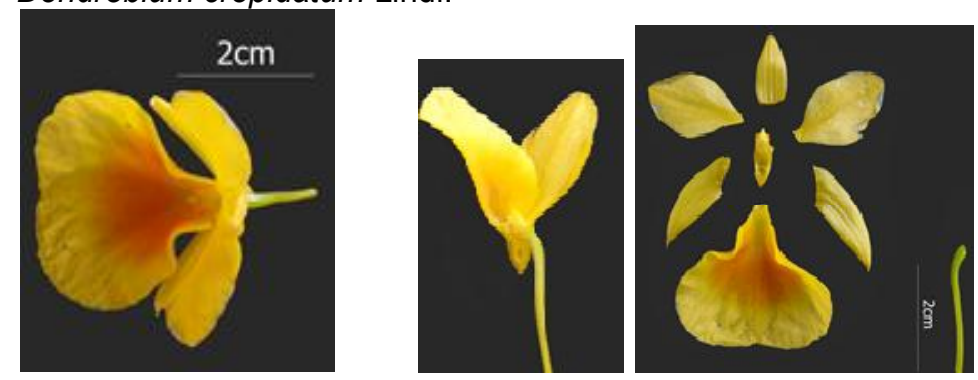

17 - Dendrobium capillipes Rchb.f. 

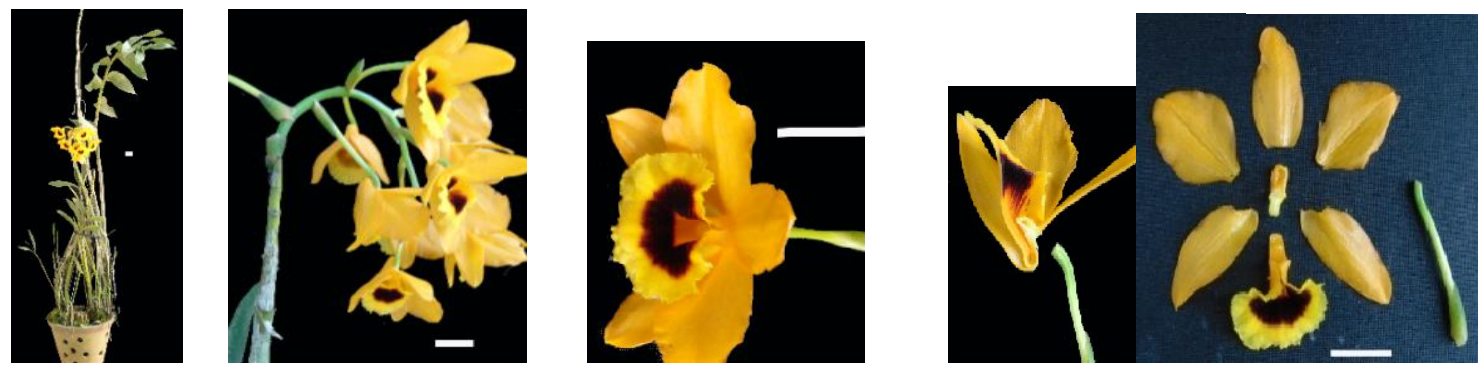

18 - Dendrobium chryseum Rolfe
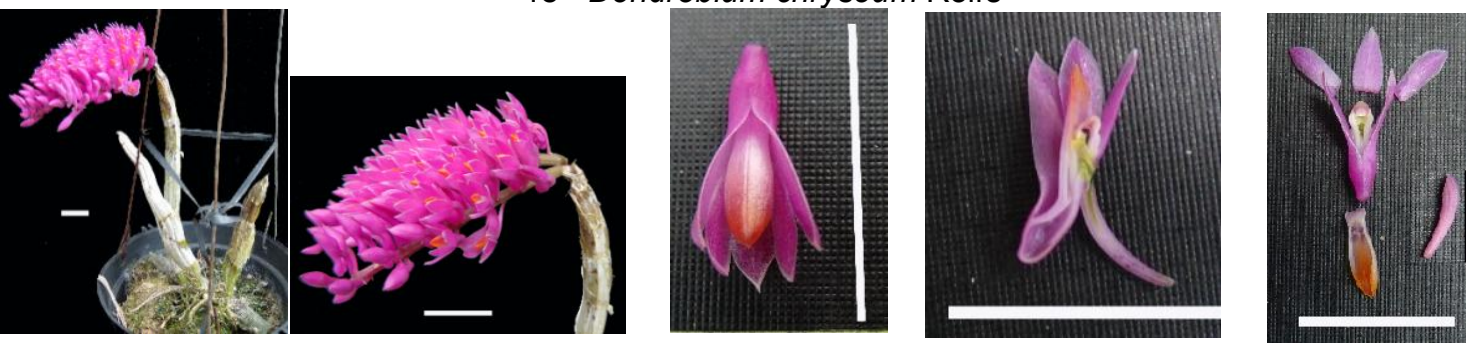

19 - Dendrobium secundum (BI.) Lindl.
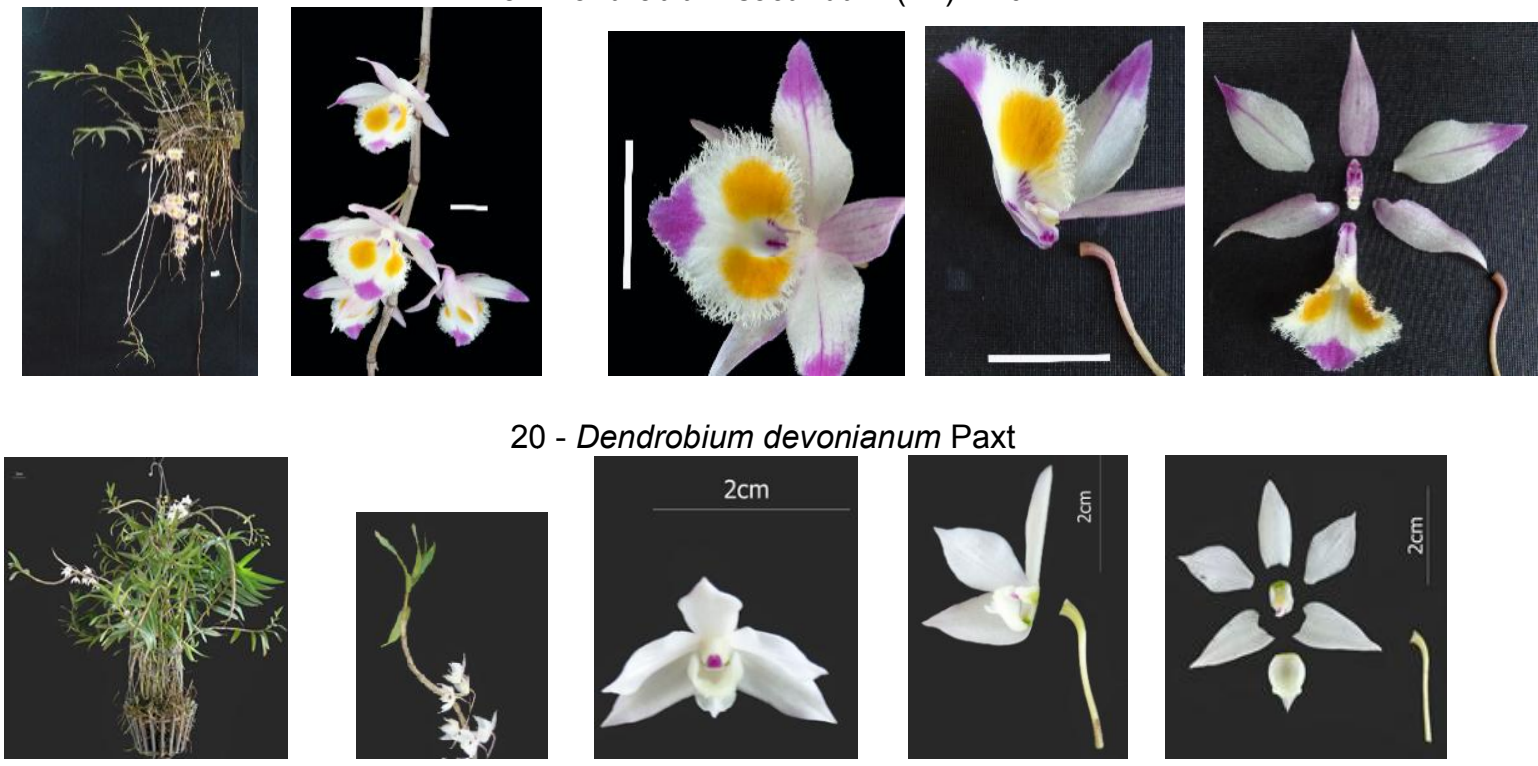

21 - Dendrobium aduncum Lindl.
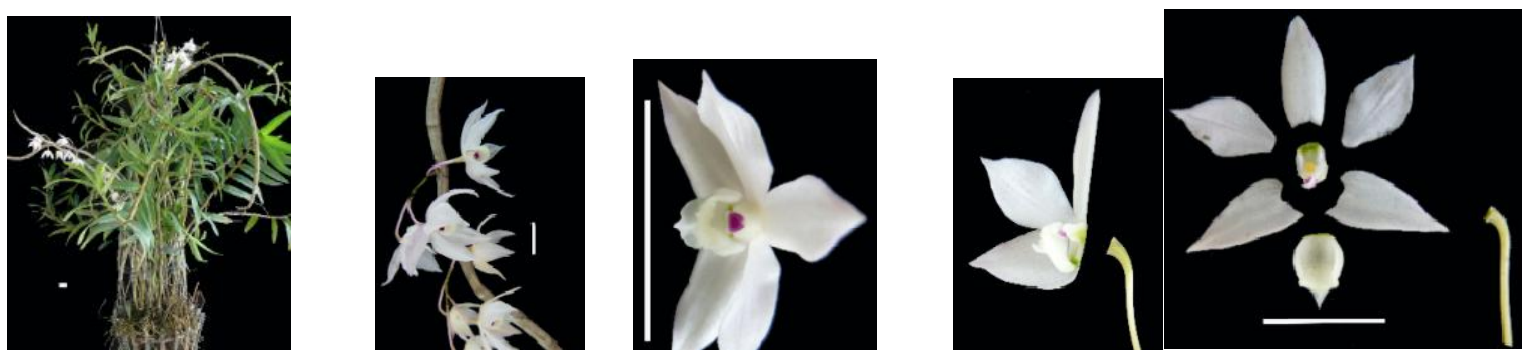

22 - Dendrobium hercoglossum Rchb. f. 

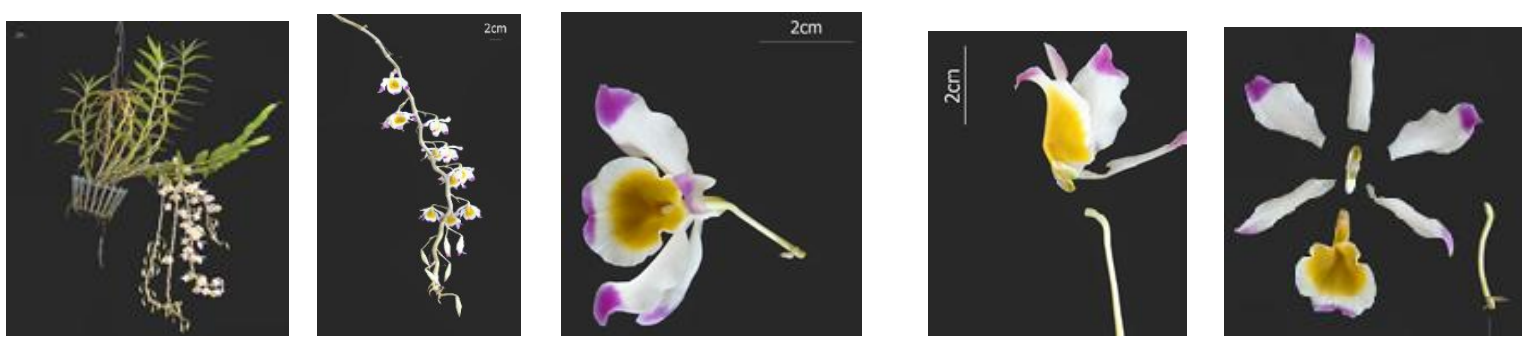

23 - Dendrobium crystallinum Rchb. f.
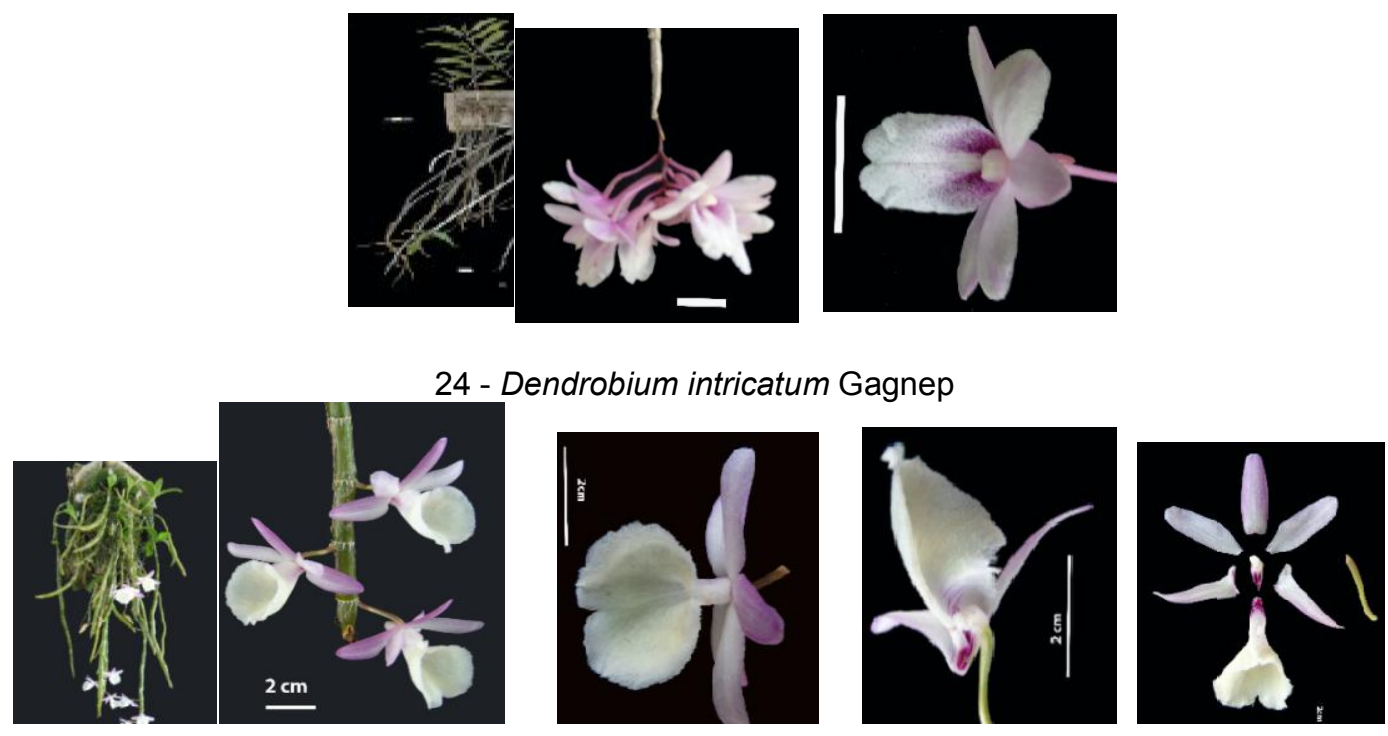

25 - Dendrobium cretaceum Lindl.
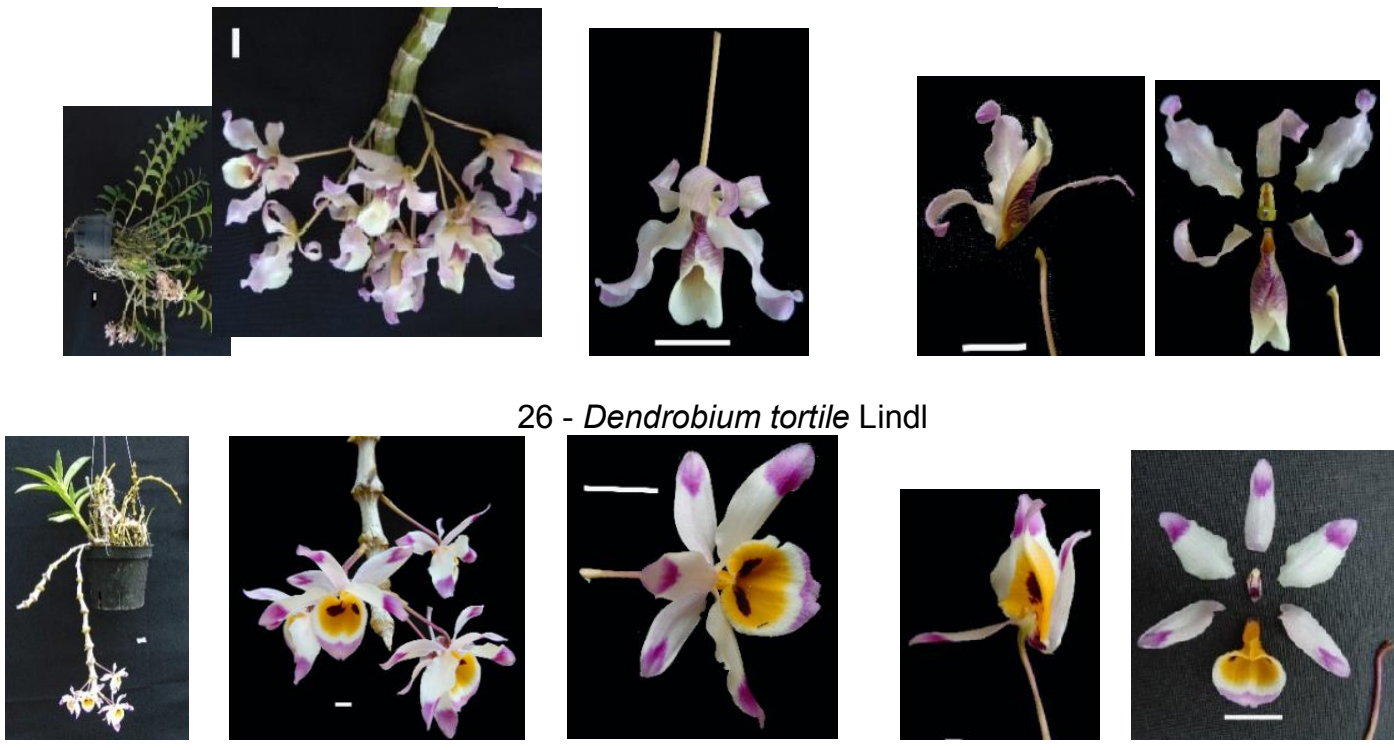

6 - Dendrobium tortile Lindl
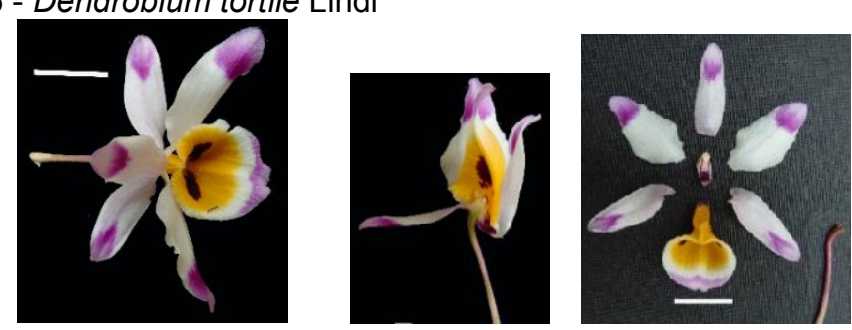

27 - Dendrobium pendulum 

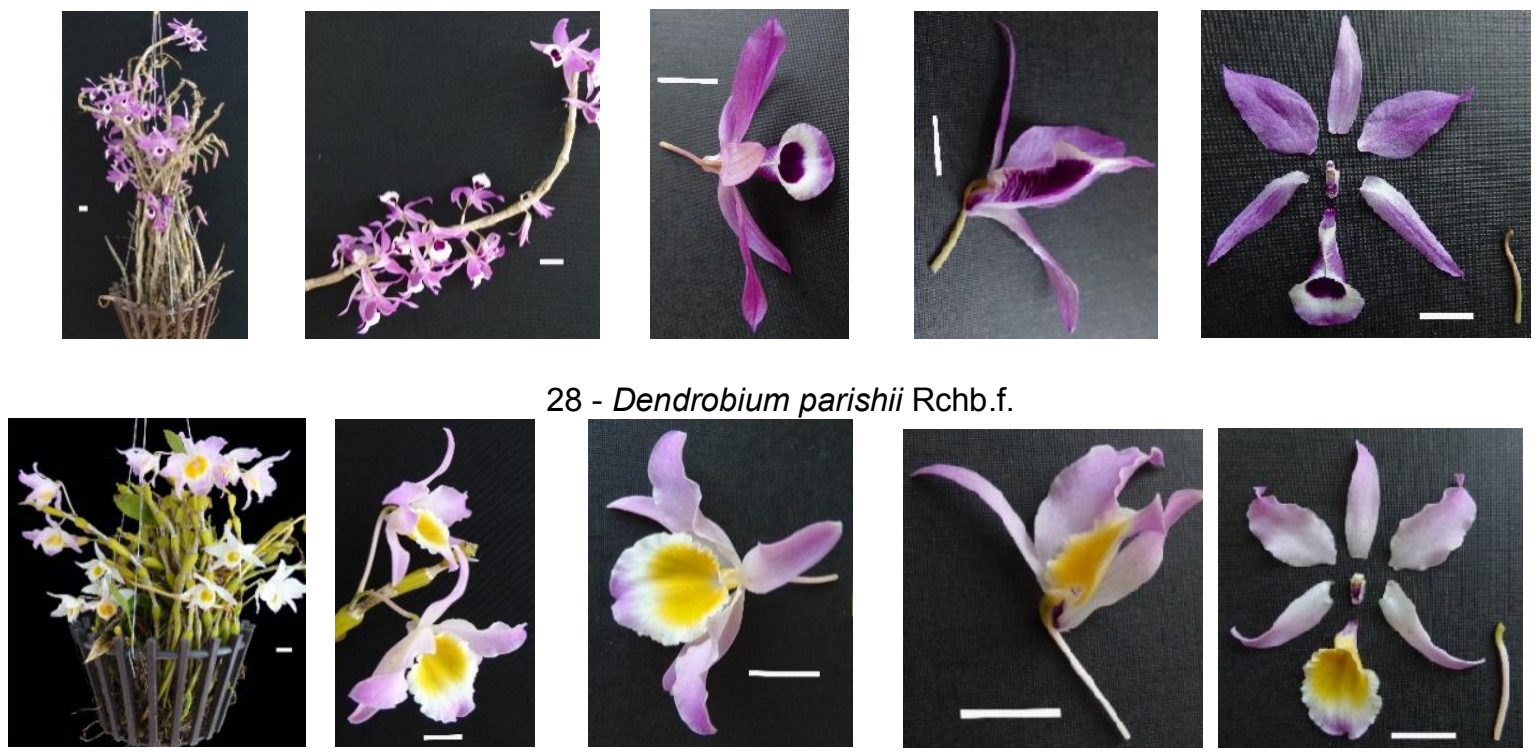

28 - Dendrobium parishii Rchb.f.
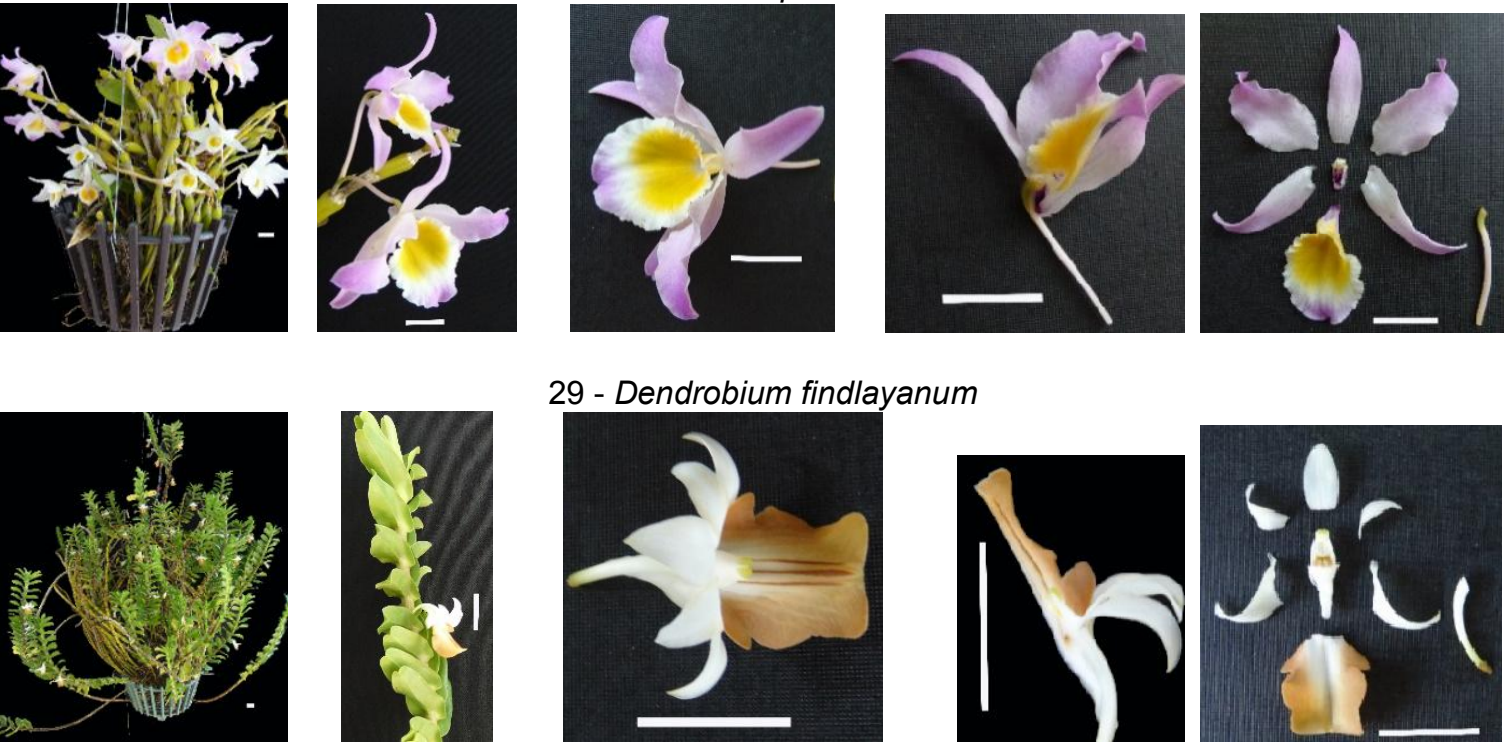

29 - Dendrobium findlayanum
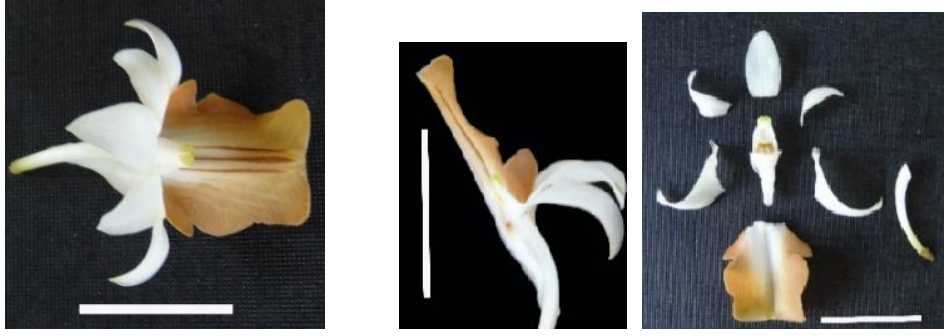

30 - Dendrobium ellipsophyllum Tang \& F.T Wang
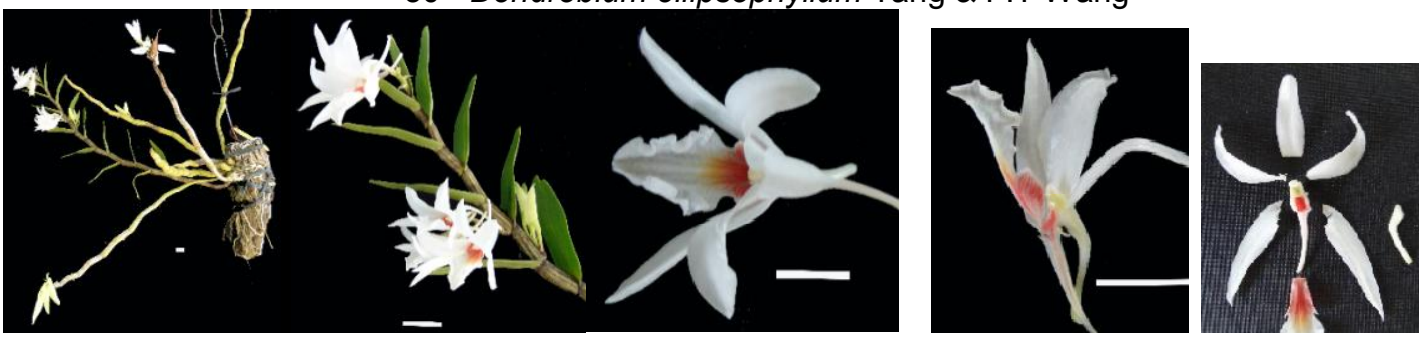

31 - Dendrobium draconis Rchb.f.
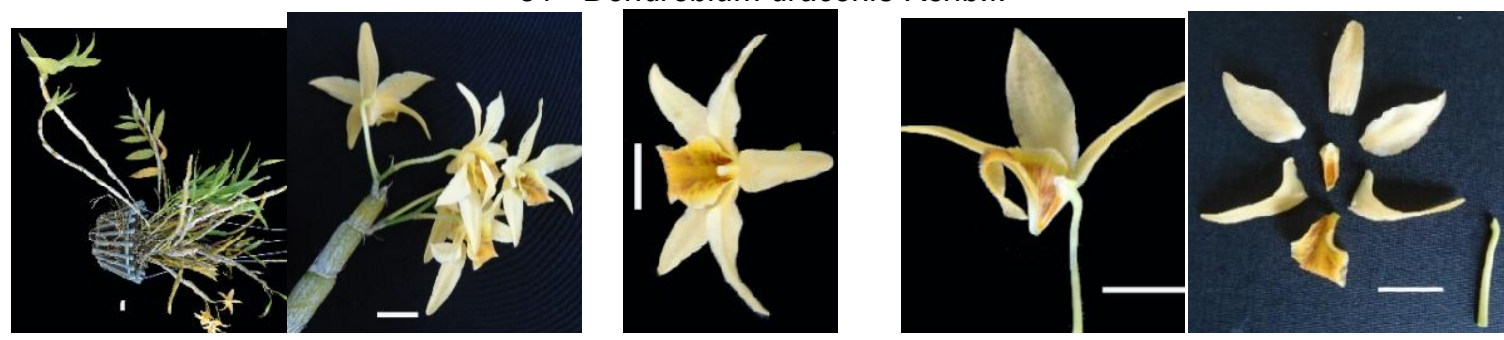

32 - Dendrobium heterocarpum Wall.ex Lindl. 

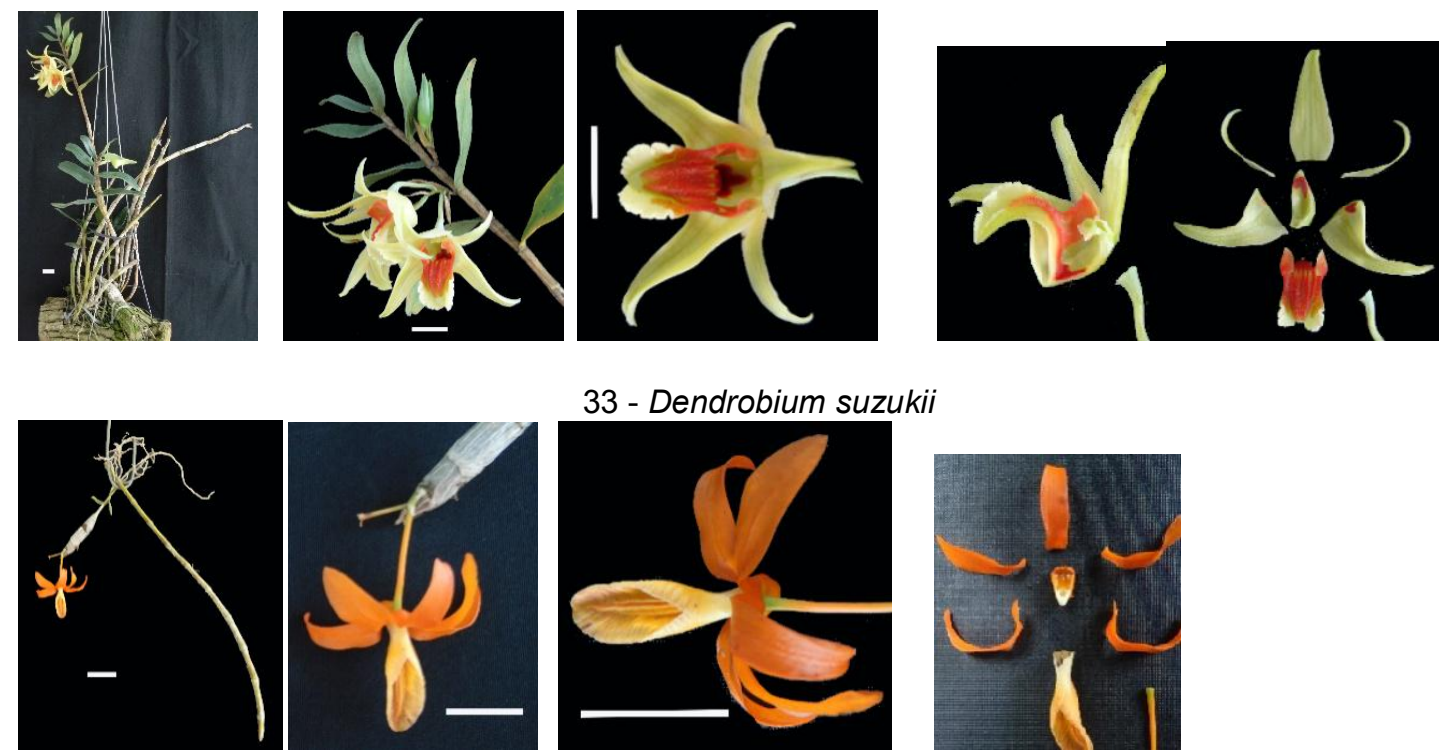

33 - Dendrobium suzukii
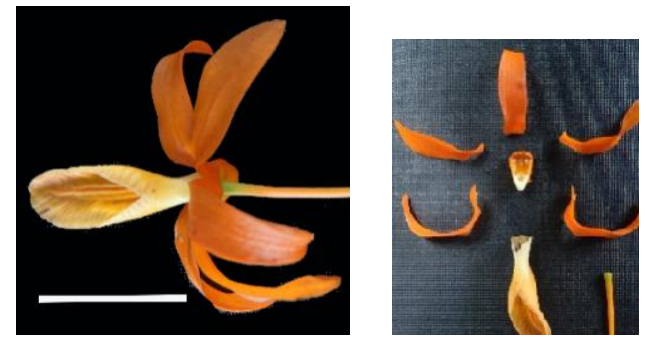

34 - Dendrobium unicum Seidenfaden 1970
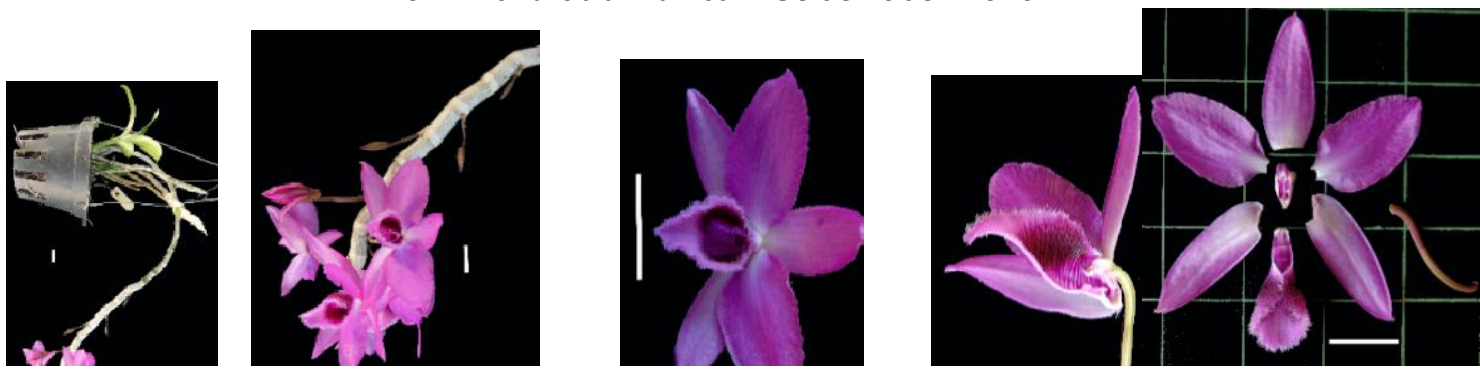

35 - (D. anosmum x D. parishii)
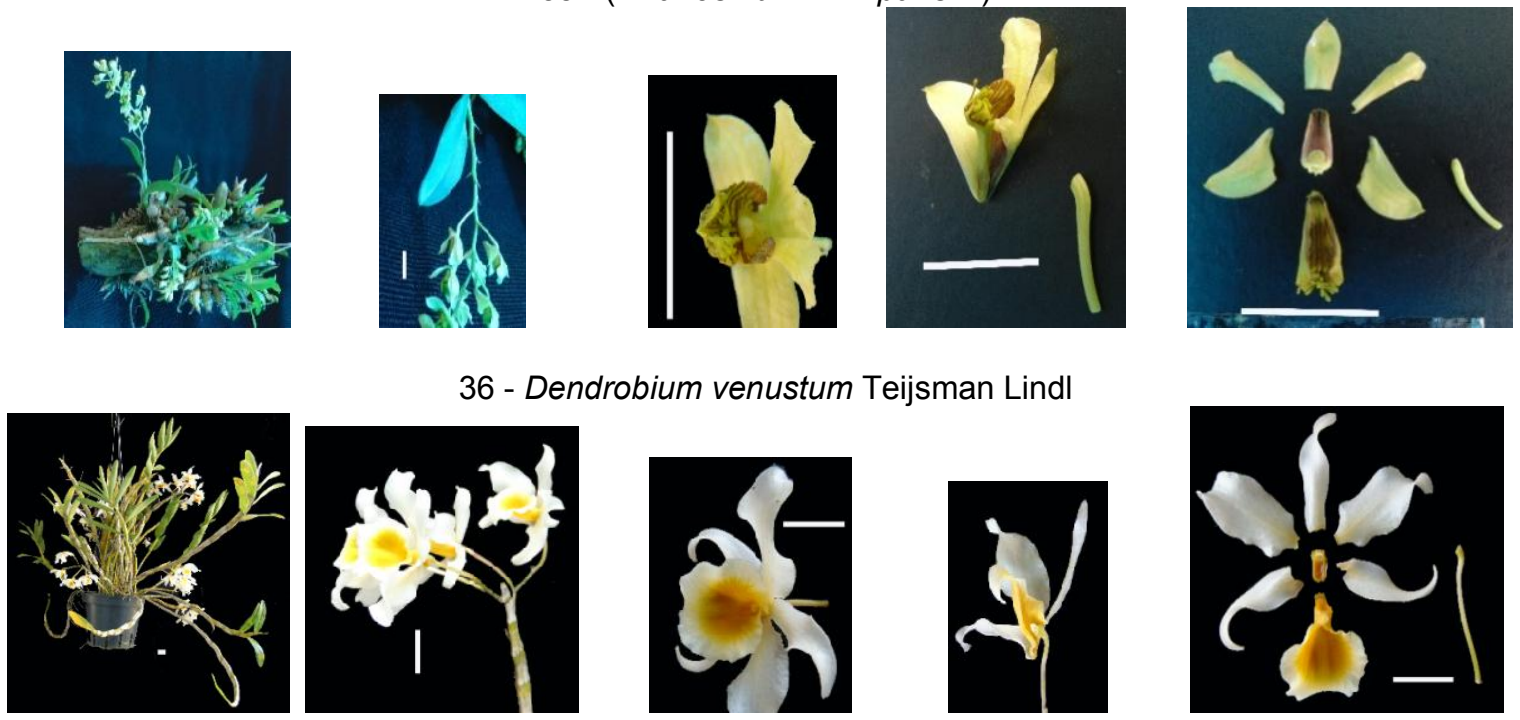

37 - Dendrobium tortile Lindl. 

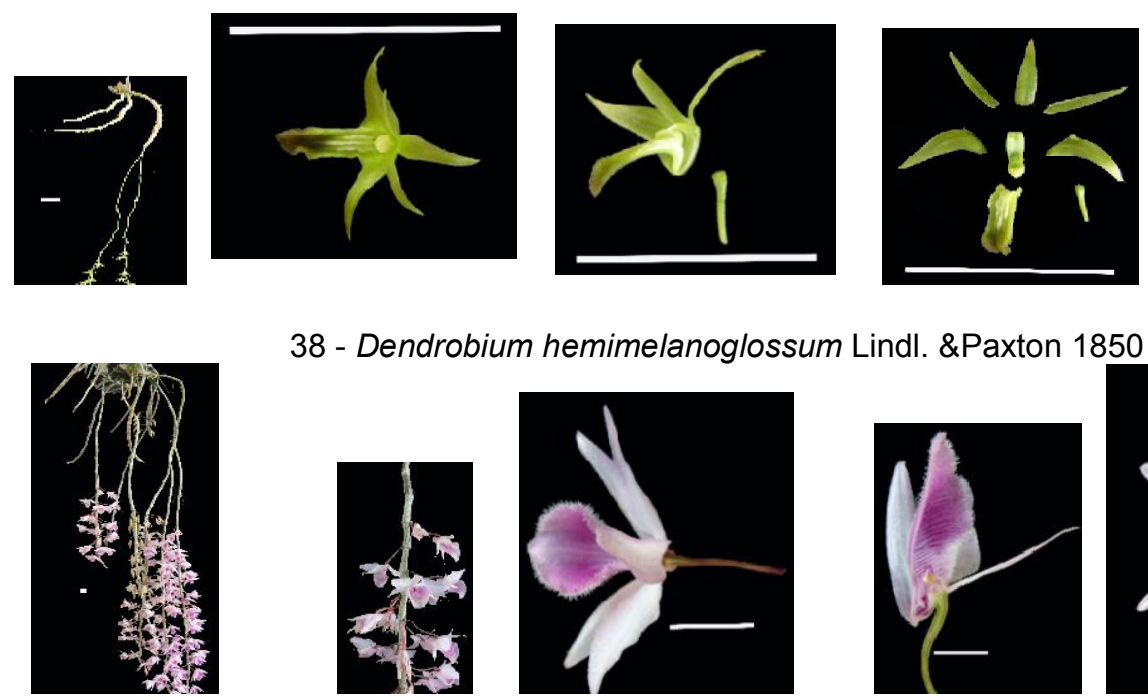

38 - Dendrobium hemimelanoglossum Lindl. \&Paxton 1850
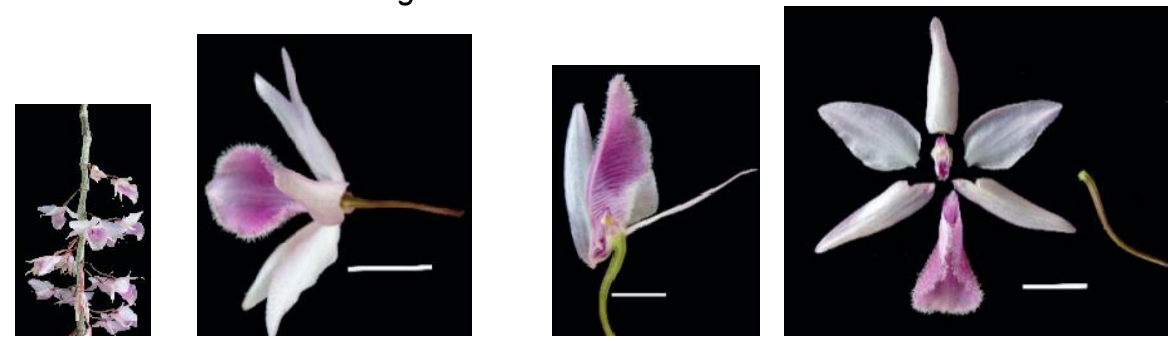

39 - D. anosmum x D. aphyllum
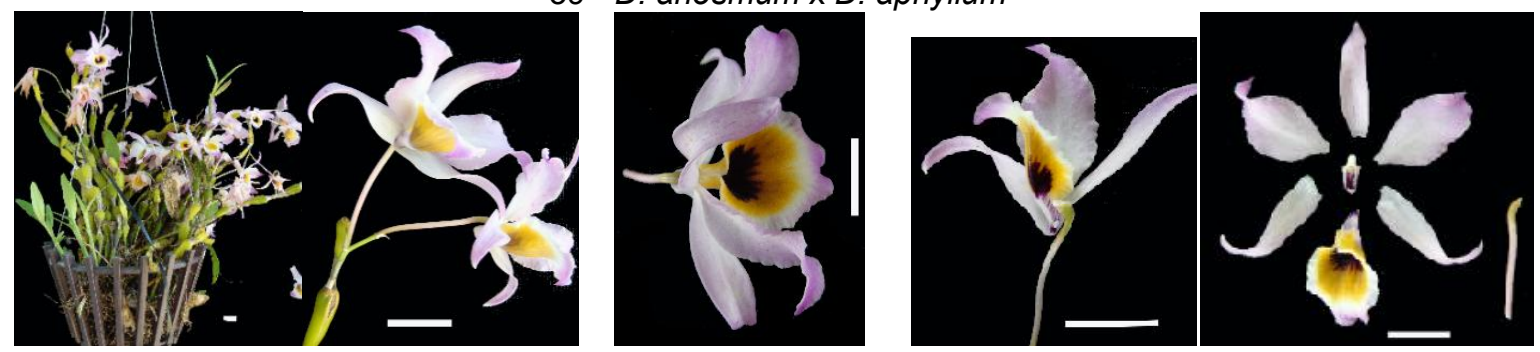

40 - Dendrobiumfindlayanum

(c) 2020 Nguyen et al.; This is an Open Access article distributed under the terms of the Creative Commons Attribution License (http://creativecommons.org/licenses/by/4.0), which permits unrestricted use, distribution, and reproduction in any medium, provided the original work is properly cited.

\section{Peer-review history:}

The peer review history for this paper can be accessed here: http://www.sdiarticle4.com/review-history/56811 